\title{
A versatile tRNA modification-sensitive northern blot method with enhanced performance
}

\author{
Abdul Khalique, Sandy Mattijssen and Richard J. Maraia* \\ Division of Intramural Research, \\ Eunice Kennedy Shriver National Institute of Child Health and Human Development, \\ National Institutes of Health, Bethesda, MD, United States
}

*Corresponding author, E-mail: maraiar@mail.nih.gov

Abbreviations: AC: anticodon, ACL: anticodon loop, AME: apparent modification efficiency, ASL: anticodon stem-loop, $\mathbf{i}^{\mathbf{6}} \mathbf{A 3 7}: N^{6}$-isopentenyladenosine-37, IPTase: isopentenyltransferase, $\mathbf{m}^{\mathbf{3}} \mathbf{C}: \mathbf{3 -}$ methylcytidine, $\mathbf{m}^{2,2} \mathbf{G}: N^{2}, N^{2}$-dimethylguanosine, OSGEP: O-Sialoglycoprotein endopeptidase, PHAM: positive hybridization in the absence of modification, $\mathbf{t}^{\mathbf{6}} \mathbf{A} 37: N^{6}$-threonylcabamoyladenosine-37, TME: tRNA modification enzyme, Ti: incubation temperature, TRIT1: tRNA isopentenyltransferase 1, TRMT1: tRNA methyltransferase 1, DALRD3: DALR anticodon binding domain containing 3. 


\begin{abstract}
The 22 mitochondrial and $\sim 45$ cytosolic tRNAs in human cells contain several dozen different posttranscriptional modified nucleotides such that each carries a unique constellation that complements its function. Many tRNA modifications are linked to altered gene expression and deficiencies due to mutations in tRNA modification enzymes (TMEs) are responsible for numerous diseases. Easily accessible methods to detect tRNA hypomodifications can facilitate progress in advancing such molecular studies. Our lab developed a northern blot method that can quantify relative levels of base modifications on multiple specific tRNAs $\sim 10$ years ago which has been used to characterize four different TME deficiencies and is likely further extendable. The assay method depends on differential annealing efficiency of an DNA-oligo probe to the modified versus unmodified tRNA. The signal of this probe is then normalized by a second probe elsewhere on the same tRNA. This positive hybridization in the absence of modification (PHAM) assay has proven useful for $\mathrm{i}^{6} \mathrm{~A} 37, \mathrm{t}^{6} \mathrm{~A} 37, \mathrm{~m}^{3} \mathrm{C} 32$ and $\mathrm{m}^{2,2} \mathrm{G} 26$ in multiple laboratories. Yet, over the years we have observed idiosyncratic inconsistency and variability in the assay. Here we document these for some tRNAs and probes and illustrate principles and practices for improved reliability and uniformity in performance. We provide an overview of the method and illustrate benefits of the improved conditions. This is followed by data that demonstrate quantitative validation of PHAM using a TME deletion control, and that nearby modifications can falsely alter the calculated apparent modification efficiency. Finally, we include a calculator tool for matching probe and hybridization conditions.
\end{abstract}




\section{INTRODUCTION}

Among all RNA species, the tRNAs are the most extensive post-transcriptionally modified both in density (\% modified nucleotides) and diversity (different modifications), collectively carrying $>100$ modified nucleotides (nts) (Vare et al. 2017; Krutyholowa et al. 2019; Suzuki 2021). Human cytoplasmic (cy) tRNAs carry as many as 17 modified nts, with an average of 13 per tRNA (Pan 2018). Each of the $\sim 45$ major cytRNA species has unique identity with a distinct combination of modified nts. Each of the 22-human mitochondrial (mt) tRNAs carry 3 to 9 modifications (Suzuki et al. 2020). Some mt-tRNA modifications are not found on cy-tRNAs and vice versa (Suzuki et al. 2020). Inborn errors of tRNA hypomodification lead to numerous pathological conditions of varying severity (Chujo and Tomizawa 2021; Suzuki 2021). Sequence-specific detection of the presence or absence of modifications on specific tRNAs can be helpful in assessing the extent of suspected or actual TME dysfunction (Abbott et al. 2014; Yarham 2014; Bednarova et al. 2017). This paper reviews a method that can do so for a subset of common modifications. Because it is applicable to modifications that share a certain physiochemical characteristic, we will first provide a general review of this aspect of the method to aid understanding and its practical use.

tRNA modifications comprise a wide range of chemical complexity. A relevant example is the diversity at position $37,3^{\prime}$ to the anticodon. Several tRNAs carry $t^{6} A 37$, while others are modified with either $N^{6}$-isopentenyladenosine-37 (i $\left.{ }^{6} \mathrm{~A} 37\right)$, a methyl addition on $N^{1}$ of G ( $\left.\mathrm{m}^{1} \mathrm{G} 37\right)$, or after deamination of adenosine to inosine to form $\mathrm{m}^{1} \mathrm{I} 37$, others remain unmodified, and tRNAs ${ }^{\text {Phe }}$ carry wybutosine (yW37) whose synthesis requires sequential enzymatic activities (Boccaletto et al. 2018) (see Lorenz et al. 2017).

The anticodon loop (ACL) which spans positions 32-38 is most variably modified due to positions 34 and 37 (Han et al. 2018; Han and Phizicky 2018), with wobble base 34 being most diverse. Modifications to 34 and 37 are important for balance of accuracy, flexibility, and efficiency of translation by controlling the thermodynamic and spatial limits of codon-anticodon pairing in the ribosome (Vare et al. 2017). Modifications to nucleotide 34 are thought of to promote correct pairing to codon position 3, especially important for wobble decoding (Agris et al. 2018). Conversely, modifications to 37 interfere with 
Watson:Crick (W:C) bonding and are thought to maintain reading frame by preventing pairing with an upstream base (Vare et al. 2017). These modifications are relevant to the assay reviewed here referred to as positive hybridization in the absence of modification (PHAM), and can be listed as $\mathrm{i}^{6} \mathrm{~A} 37, \mathrm{t}^{6} \mathrm{~A} 37, \mathrm{~m}^{1} \mathrm{G} 37$, $\mathrm{m}^{1} \mathrm{I} 37$ and $y \mathrm{~W} 37$, as well as hypermodified forms, e.g., $\mathrm{mS}^{2} \mathrm{i}^{\mathbf{6}} \mathrm{A} 37$ resulting from methylthiolation of $\mathrm{i}^{\mathbf{6}} \mathrm{A} 37$ in mammalian but not yeast mitochondria, and in bacteria (Wei et al. 2015; Lamichhane et al. 2016). The PHAM method has also been applied to $N^{2}, N^{2}$-dimethylguanosine-26 $\left(\mathrm{m}^{2,2} \mathrm{G} 26\right)$, and $N^{3}$-methylcytosine $\left(\mathrm{m}^{3} \mathrm{C}\right.$ ) at position 32 in tRNAs Ser, Thr and Arg (and other locations) which also have this characteristic.

The anticodon stem loop (ASL) directs "modification circuits" in which a modification at one position is pre-requisite for a sequential modification at one or more position elsewhere in the ACL. Some of the known circuits are disrupted by disease-causing mutations in TMEs (Guy and Phizicky 2014; Guy et al. 2015; Li et al. 2020) (reviewed in Barraud and Tisné 2019) (and in Sokolowski et al. 2017). The PHAM assay has been used to monitor three ACL circuit modifications, $\mathrm{i}^{6} \mathrm{~A} 37, \mathrm{t}^{6} \mathrm{~A} 37$ and $\mathrm{m}^{3} \mathrm{C} 32$, and to document heritable errors of metabolism due to mutations to the TMEs involved in their synthesis (Yarham 2014; Edvardson et al. 2017; Lentini et al. 2020; Lentini et al. 2021). It was also used for another translationallyactive ASL modification, $\mathrm{m}^{2,2} \mathrm{G} 26$ whose deficiency also causes a human disease (Dewe et al. 2017).

Notable gel-based assays can distinguish between the presence and absence of a particular modified nucleotide in a tRNA-specific manner. The modified nucleotide, queuosine (Q) has been targeted by multiple approaches (Igloi and Kössel 1985; Zaborske et al. 2014; Wang et al. 2018; Matuszek and Pan 2019). Acryloylamino-phenylboronic (APB) acid is used to exploit a chemical reactivity highly limited to Q (Zaborske et al. 2014). APB interacts with Q in tRNA, slowing its mobility in APB-gels (in addition to above also see Kessler et al. 2018; Cirzi and Tuorto 2021); in species in which Q is glycosylated, an adaptation can be incorporated (Zhang et al. 2020). A unique tRNA-specific approach was developed for northern blot detection of yW37 found on a single tRNA, the isoacceptor for Phe (Nostramo and Hopper 2020). This exploits the specific reactivity of $y \mathrm{~W}$ with aniline followed by hydrolysis with mild acid. Upon 
specific probing, $\mathrm{tRNA}^{\mathrm{Phe}}$ that contains yW37 exhibits a distinctive cleavage pattern while tRNA ${ }^{\text {Phe }}$ lacking yW37 remains full length (Nostramo and Hopper 2020).

Annealing of cellular RNA to DNA-oligo arrays was found sensitive to certain modifications, that interfere with base-pairing as discussed above for PHAM, and these were verified using TME deletion strains (Hiley et al. 2005). Methylation of atoms normally involved in hydrogen bond formation that enable W:C base-pairing interferes with this, such as $\mathrm{m}^{1} \mathrm{~A}, \mathrm{~m}^{1} \mathrm{G}, \mathrm{m}^{3} \mathrm{C}$ and $\mathrm{m}^{2,2} \mathrm{G}$ (Fig 1A-C). These methylated bases can be discerned by some reverse transcriptase (RT)-mediated cDNA-based tRNAseq methods (Ryvkin et al. 2013; Arimbasseri et al. 2015; Cozen et al. 2015; Zheng et al. 2015; Arimbasseri et al. 2016; Clark et al. 2016; Gogakos et al. 2017; Hrabeta-Robinson et al. 2017; Guo et al. 2020; Behrens et al. 2021) (reviewed in Motorin and Marchand 2021). In cDNA Seq methodologies, the RTs have trouble 'identifying' bases that are methylated/modified on atoms involved in $\mathrm{W}: \mathrm{C}$ hydrogen bond formation and a 'mis'matched dNTP is 'mis'-incorporated, sometimes with a particular frequency or 'signature' specific to a particular RT (e.g., supp figures 2 and 3 in Arimbasseri et al. 2015; Gogakos et al. 2017; Behrens et al. 2021). Mismatches in cDNA hydro-tRNAseq data at positions in specific tRNAs known to be modified with $\mathrm{m}^{2,2} \mathrm{G} 26$ and $\mathrm{m}^{3} \mathrm{C} 32$ were validated by their appearance as the correct sequence in $S$. pombe strains deleted of the TME genes for $\operatorname{trm} 1^{+}$and $t r m 140^{+}$respectively, encoding the respective methyltransferases (Arimbasseri et al. 2015; Arimbasseri et al. 2016). Likewise $\mathrm{m}^{1} \mathrm{G} 9, \mathrm{~m}^{\mathbf{2}, 2} \mathrm{G} 26$ and yW37-related mismatches in cDNA mim-tRNAseq data from $S$. cerevisiae were validated by the trm10 $\Delta$, trm $1 \Delta$ and trm7 $\Delta$ strains respectively (Behrens et al. 2021). Pre-treatment of RNA samples with demethylases convert mismatches in cDNA Seq data to the correct nucleotides (Cozen et al. 2015; Zheng et al. 2015; Clark et al. 2016; Behrens et al. 2021). Thanks to tRNA modification databases not only can mismatches in cDNA data can be "called" as modifications but can also be used to substantially improve tRNA alignment to reference genomes (Behrens et al. 2021). In this way, cDNA-tRNAseq has been advanced to reliably quantify relative tRNA abundances (Behrens et al. 2021). In any case, conventional methods should validate or determine modifications at unexpected mismatch positions in cDNA-based sequences (Helm and Motorin 2017). 
Not only base methylations, but a limited number of other modifications including to the ribose, can also be detected by cDNA Seq approaches (Clark et al. 2016; Guo et al. 2020), as well as inosine which is misread as guanosine due to loss of hydrogen bonding by deamination of adenosine (Arimbasseri et al. 2015). Still, the number of modifications discernable by mismatches is limited, even though this can be increased by examination of other patterns in the cDNA data such as positional stops (Clark et al. 2016).

Certain base methylations to atoms involved in hydrogen bonding on the $\mathrm{W}: \mathrm{C}$ face, e.g., $\mathrm{m}^{6} \mathrm{~A}$ and $\mathrm{m}^{2} \mathrm{G}$ do not lead to mismatches in cDNA tRNAseq data; methylation of the primary amines at $N^{6}$ of A and $N^{2}$ of G leave one of the hydrogens available for hydrogen bond formation. Even large modifications to $N^{6} \mathrm{~A}$ such as $i^{6} \mathrm{~A} 37$ and $\mathrm{t}^{6} \mathrm{~A} 37$ were not associated with mismatches in the cDNA tRNAseq data (Arimbasseri et al. 2015; Clark et al. 2016) nor did they block RT unless hypermodified (Behrens et al. 2021). Yet these have been very good candidates for PHAM (below).

General description of the PHAM method and its application. High throughput tRNAseq methods can deliver information on all cellular tRNAs and some modifications but requires significant investment in bioinformatics and other resources. The PHAM blot method requires less investment and set-up. It exploits the high sensitivity of DNA-oligo probe annealing to a tRNA sequence due to impaired base pairing caused by modification of the nucleotide under study. A single PHAM blot can be used to survey multiple specific tRNAs and can detect and quantify some modifications that cDNA-seq methods cannot.

As illustrated in Figs $1 \mathrm{~A}$ and $\mathrm{D}$, the $N^{6}$ isopentenyl group on adenine (i $\left.{ }^{6} \mathrm{~A} 37\right)$ would limit W:C base pairing. As shown previously and illustrated in Fig 1E, presence of $i^{6} \mathrm{~A} 37$ is discernable by the PHAM assay (Lamichhane et al. 2011; Lamichhane et al. 2013a; Lamichhane et al. 2013b; Yarham 2014; Lamichhane et al. 2016; Khalique et al. 2020), and is also applicable to t ${ }^{6} \mathrm{~A} 37$ (Rojas-Benitez et al. 2015; Edvardson et al. 2017; Bacusmo et al. 2018; Beenstock et al. 2020). The $\mathrm{m}^{3} \mathrm{C} 32$ and $\mathrm{m}^{2,2} \mathrm{G} 26$ which block the possibility for hydrogen bond formation for W:C base-pairing (Fig 1C) are also discernable by PHAM (Arimbasseri 
et al. 2015; Bacusmo et al. 2018; Lentini et al. 2020; Lentini et al. 2021). Schematics for $\mathrm{m}^{\mathbf{1}} \mathrm{A}$ and $\mathrm{m}^{\mathbf{1}} \mathrm{G}$ which also block hydrogen bond formation are shown along with I and $\mathrm{m}^{1} \mathrm{I}$ (Fig 1B).

tRNA isopentenyltransferase-1 (Tit1) is the TME responsible for $i^{6} \mathrm{~A} 37$ formation. Fig 1E illustrates PHAM for cy-tRNA ${ }^{\mathbf{T y r}} \mathrm{GUA}$; the left shows RNA from two fission yeast strains, Schizosaccharomyces pombe yNB5 (tit1 $\Delta$, deleted of the $t i t 1^{+}$gene) and yYH1 $\left(t i t 1^{+}\right)$. The right side illustrates that the ACL probe efficiently anneals to A37-unmodified tRNA ${ }^{\text {Tyr }}$ GUA from tit1 $\Delta$ cells but not to ${ }^{6} \mathrm{~A} 37$-modified tRNA ${ }^{\text {Tyr }}$ GUA from $t i t 1^{+}$cells. After initial probing, the blot was stripped of ACL probe, rescanned to ensure that the signal was efficiently removed, and reprobed with a "body probe" (BP) to the T stem-loop region of the cytRNA $^{\text {Tyr }}$ GUA showing more or less equal loading (Fig 1E, lower left panel).

We want to highlight that for $\mathrm{i}^{6} \mathrm{~A} 37, \mathrm{t}^{6} \mathrm{~A} 37, \mathrm{~m}^{2,2} \mathrm{G} 26$ and $\mathrm{m}^{3} \mathrm{C} 32$, PHAM was used to document tRNA hypomodification as a functional manifestation of newly described TME deficiencies in human disease syndromes due to mutations in TRIT1 (Yarham 2014), OSGEP (Edvardson et al. 2017), TRMT1 (Dewe et al. 2017) and DALRD3 (Lentini et al. 2020), respectively. In addition, a pathogenic mutation at the 38 position of mt-tRNA ${ }^{\text {Ser }} \mathrm{UCN}$ was shown to result in tRNA-i ${ }^{6} \mathrm{~A}$ hypomodification at position 37 (Yarham 2014), consistent with the A36-A37-A38 recognition sequence of IPTases (Motorin et al. 1997).

A five-step outline with graphics and notes comprises Fig 2. The major steps are 1) RNA preparation/purification, 2) Polyacrylamide gel electrophoresis-northern blotting, 3) Probing with a modification-detection DNA-oligo followed by washing and exposure, 4) Blot stripping and probing by a calibration DNA-oligo, washing and exposure and 5) Quantification of hybridization band signals. Steps 1 and 2 each take one day or more, whereas the other steps take longer depending on signal strength and exposure times needed for quantifiable results.

Calculation of apparent modification efficiency (AME) \%. The following basic equation is used to convert quantified data into AME \%=〔1-(ACL (test sample)/BP (test sample))/(ACL (background)/BP 
(background)) ] $\mathrm{x} 100$, where $\mathrm{ACL}=$ quantity of counts from the ACL probe, and BP = quantity of counts from the BP (control) probe. See below and Figs for specific cases.

The PHAM method described with real data to illustrate key points. Of the three points we want to convey in the next sections, the first is the most important, 1) Different tRNAs exhibit different response profiles to ACL probe washing at temperatures above the incubation temperature (Ti). This led to a protocol in which wash temperature must be empirically determined for each ACL probe the first time it is used/tested for optimal performance and quantification. The second and third points are 2) in general, mttRNAs exhibit greater sensitivity to increasing ACL probe wash temperatures than cy-tRNAs, and 3) nearby modifications lead to false elevation of the apparent modification efficiency (AME) of the target nucleotide.

Other cautionary notes are worthy of mention. The PHAM assay is based on differential annealing efficiency of a DNA-oligo to two or more sample tRNAs that vary in their levels of modification at a particular position of interest. Another DNA-oligo probe that anneals to a different region of the same tRNA serves as a control for normalization/calibration. One should be cautious as discussed above if the target nucleotide is part of a modification circuit, because of the possibility that another modification in the region complementary to the probe would alter annealing. Thus, one should consider reviewing the known circuits (Barraud and Tisné 2019) and perhaps a specific appropriate control experiment.

For probe design, the target nucleotide is generally opposite a central position in the oligo sequence. Supplementary Table S1 is a spreadsheet that can calculate the hybridization Ti for the DNA-oligo ACL probe and body probe (BP) for the salt conditions of the hybridization solution (2X SSC). In the next section we compare fission yeast $S$. pombe strains that differ in the presence and absence of the tit $1^{+}$gene responsible for $\mathrm{i}^{6} \mathrm{~A} 37$ formation.

\section{1) Different tRNAs exhibit different profiles to ACL probe washing at temperatures above $\mathrm{Ti}$.}

Because each tRNA has a unique nucleotide sequence and modification profile in an organism, the DNA 
probe annealing can be different for each and may also vary among species for similar tRNAs. The $\mathrm{i}^{6} \mathrm{~A} 37$ AME for different tRNAs were analyzed by PHAM at multiple increments of wash temperatures above the Ti of the ACL probe. Annealing of an ACL probe is diminished by modification-induced loss of hydrogen bond formation and possibly steric hindrance in the presence of $\mathrm{i}^{6} \mathrm{~A} 37$. This results in lower probe signal on the northern blot for $\mathrm{i}^{6} \mathrm{~A} 37$-modified tRNA relative to unmodified tRNA. The goal below was to determine if wash temperature altered differential ACL:BP signal ratio and therefore the calculated AME $\%$, and importantly if it would be different for different tRNAs.

Two cy-tRNA substrates, tRNA ${ }^{\text {Ser }}$ AGA and tRNA $^{\text {Tyr }}$ GUA were examined at increasing wash temperatures above the $\mathrm{Ti}$ of the ACL probes, $\mathrm{Ti}+5^{\circ} \mathrm{C},+10^{\circ} \mathrm{C},+15^{\circ} \mathrm{C}$ and $+17.5^{\circ} \mathrm{C}$. The ACL Ti for tRNA ${ }^{\text {Ser }} \mathrm{AGA}=51.2^{\circ} \mathrm{C}$, and for tRNA ${ }^{\mathrm{Tyr}} \mathrm{GUA}=54.3^{\circ} \mathrm{C}$. These tRNAs carry $\mathrm{i}^{6} \mathrm{~A} 37$ in yYH1 $\left(\right.$ tit $1^{+}$) cells but lack it in yNB5 (tit1 $\Delta$ ). Both probes anneal better to tRNAs from tit1 $\Delta$ than from tit1 $^{+}$cells (Fig $3 \mathrm{~A}$, B).

As is routinely observed, probe annealing and signal strength decreases as wash temperature increases, as expected (data not shown). Importantly however we observed that the differences in changes for the two tRNAs differed as the wash temperature increased, and with different optima (Fig 3A, B). The AME in Fig 3C, based on duplicate experiments also reflects the differential patterns. The tRNA ${ }^{\text {Ser } A G A}$ showed a steeper incline than tRNA ${ }^{\text {Tyr }}$ GUA to the optimal temperature (Fig 3C). More important, wash temperatures of $\mathrm{Ti}+15^{\circ} \mathrm{C}$ or higher led to higher AMEs in $t i t 1^{+}$cells (Fig 3C). This latter point was demonstrated a most relevant benefit in the case of mt-tRNAs (see below and Discussion).

The data suggest that quantification of intermediate levels of modification can be assessed when positive controls are at $\sim 90 \%$ and negative controls ( $0-10 \%)$, the latter based on TME deletion or persistent high efficiency knock-down, because tRNA half-lives can be $\sim 60$ hours (Abelson et al. 1974). Synthetic unmodified RNA could suffice as a null control although its probe annealing efficacy may differ from cellular tRNA that lack a modification due to a TME deficiency. It may be useful to note alternative methods for estimating TME deficiency, for example in patient cells compared to control cells. A prior report set the 
quantifications of BP/ACL for control cells to $100 \%$ and compared this to BP/ACL from patient cells (Yarham 2014).

\section{2) Mitochondrial tRNA-ACL probes may show wide range or acute sensitivity to wash temperatures.}

While a larger number of modifications are found on cy-tRNAs than on mt-tRNAs, some are unique to either, and a small subset is found on both (Suzuki et al. 2020). During our studies, we observed that some mt-tRNAs exhibit steep incline in response to wash temperature which is observed in Fig 4 for $S$. pombe

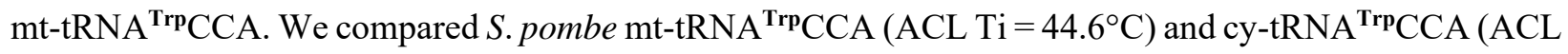
$\left.\mathrm{Ti}=44.6^{\circ} \mathrm{C}\right)$, both of which carry $\mathrm{i}^{6} \mathrm{~A} 37$ in $\mathrm{yYH} 1$, tit1 ${ }^{+}$and lack it in yNB5, tit1 $($Fig $4 \mathrm{~A}, \mathrm{~B})$. The mttRNA retained more ACL probe at lower temperature relative to the cy-tRNA, but it washed off as the temperature was increased (Fig 4A, B). Quantification of data from duplicate experiments led to a greater range AME \% for the mt-tRNA at varying wash temperatures as compared to the cy-tRNA (Fig 4C).

We note that conditions previously reported for the PHAM assay led to calculated AME for S. pombe mt-tRNA ${ }^{\text {Trp }}$ CCA at only $\sim 25 \%$ using tit1 $\Delta$ as negative control ( $0 \%$ mod) (Lamichhane et al. 2013a; Lamichhane et al. 2013b; Lamichhane et al. 2016) (Fig 4A). Likewise, human mt-tRNA ${ }^{\text {Ser (UCN) }}$ and mttRNA $^{\text {Trp }}$ was calculated at $50 \%$ and $40 \%$ respectively and others lower, while human cy-tRNA ${ }^{\text {Ser } U G A ~ w a s ~}$ at $\sim 95 \%$ (Lamichhane et al. 2013b). Notably, AME here went to $\sim 40 \%$ at $\mathrm{Ti}+5^{\circ} \mathrm{C}$ for $S$. pombe mttRNA ${ }^{\text {Trp }} \mathrm{CCA}$ but to $\sim 95 \%$ at $\mathrm{Ti}+15^{\circ} \mathrm{C}$ (Fig $4 \mathrm{~A}, \mathrm{C}$ ). Thus, Fig $4 \mathrm{~A}-\mathrm{C}$ demonstrate relatively large differences between mt- and cy- tRNAs in response to wash conditions. We have also observed similar disparities for S. cerevisiae mt-tRNA ${ }^{\text {Tyr }}$ and cy-tRNA ${ }^{\text {Tyr }}$ GUA and for human mt-tRNAs ${ }^{\text {Ser (UCN) }}$ and ${ }^{\text {Tyr }}$. In summary, the data indicate tRNA-specific sensitivities to wash temperatures for some mt-tRNAs and suggest careful monitoring using positive and negative controls as in Figs 3 and 4 to obtain optimal performance. In a later section we demonstrate PHAM performance to quantify intermediate levels of $\mathrm{i}^{6} \mathrm{~A} 37$ modification. 


\section{3) Nearby modifications may falsely alter the apparent modification efficiency of a target nucleotide.}

If the target modification-sensitive probe is complementary to a second (nearby) modification that interferes with W:C base pairing, the second can offset the calculated AME. To examine the effect of a second modification, $\mathrm{m}^{2,2} \mathrm{G} 26$ on detection and quantification of the target modification of interest, ${ }^{6} \mathrm{~A} 37$, we made use of three IPTases with different activities for a tRNA substrate to reveal it to different extents. While $S$.

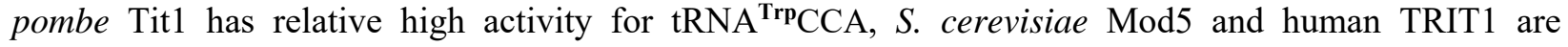
specifically less active for modification of this tRNA, which unlike all other sense-decoding IPTase substrates has pyrimidines in the 34 and 35 positions (Lamichhane et al. 2011; Khalique et al. 2020).

We designed two ACL probes to detect $\mathrm{i}^{6} \mathrm{~A} 37$, one overlapping and the other non-overlapping the G26 position of cy-tRNA ${ }^{\text {Trp }} \mathrm{CCA}$ expressed from a plasmid in IPTase-deleted $(\bmod 5 \Delta)$ MT8 cells, also expressing Tit1, Mod5 or TRIT1 (Fig 5). ACL probe 1 (P1) is complementary to positions 24-46 of tRNA ${ }^{\text {Trp }} \mathrm{CCA}$, including G26 which is modified to $\mathrm{m}^{\mathbf{2}, \mathbf{2}} \mathrm{G} 26$ in this tRNA species (Fig 5A) (Arimbasseri et al. 2015). ACL probe 2 (P2) is complementary to positions 28-50, avoiding G26 (Fig 5A). The control body probe (BP) was to the T stem-loop region. As expected, the probes detected no tRNA in cells lacking the cy-tRNA ${ }^{\text {Trp }}$ CCA expression plasmid (Fig 5B, lane 1). ACL probes P1 and P2 were comparably washed at $\mathrm{Ti}+10^{\circ} \mathrm{C}$. High signal with both ACL probes in MOD5 and TRIT1 cells reflects low $\mathrm{i}^{6} \mathrm{~A} 37$ levels on cytRNA ${ }^{\text {Trp }}$ CCA relative to $t i t 1^{+}$which as expected shows lower ACL signal (Fig 5B) (Khalique et al. 2020).

Visual inspection reveals that the ACL signal ratios for MOD5:tit $1^{+}$and TRIT1:tit $1^{+}$are higher with P2 than with P1 (Fig 5B, compare lanes $2 \& 4$, and $3 \& 4$ ). The P1 and P2 quantification data, each corrected by the corresponding BP data led to substantial differences in the calculated AMEs (Fig 5C). This analysis provided evidence that a nearby second modification can interfere with the annealing of an overlapping complimentary probe and falsely alter the calculated AME of the target nucleotide. Use of IPTases with relatively low activity for cy-tRNA ${ }^{\text {Trp }}$ CCA suggest that such artifactual elevation of AME may be enhanced at low levels of modification of the principal target nucleotide. These data indicate that it is important to design probes to avoid overlap of a second modified nucleotide(s) with base pair disrupting characteristics. 
Quantitative validation of PHAM using a yeast TME deletion control. We did a mixing experiment, of S. pombe yYH1 $\left(\right.$ tit $\left.^{+}\right)$and yNB5 (tit1A) RNAs, to examine quantitative performance of the PHAM northern blot method. We quantified and calculated $i^{6} \mathrm{~A} 37$ AME $\%$ for cy-tRNAs ${ }^{\text {Ser }}$ AGA and ${ }^{\text {Tyr }}$ GUA in duplicate, of mixes of total RNAs purified from tit ${ }^{+}$and tit1 $\Delta$, containing $0 \%, 25 \%, 50 \%, 75 \%$ and $100 \%$ of each as indicated above the lanes of Fig 6A and B. The blots were hybridized, washed, stripped, processed, and quantified according to the PHAM protocol method. Fig 6A and B shows one blot processed for both tRNAs. Fig 6A shows that as the fraction of modified tRNA increased ( $t^{+}{ }^{+}$, from left to right), annealing of the ACL probe to tRNA ${ }^{\text {Tyr }}$ GUA decreased as the wash temperature increased, which resulted in higher

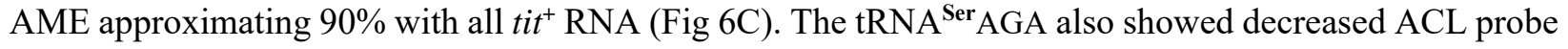
annealing with increasing tit $^{+}$tRNA as wash temperature increased (Fig 6B, mature), also resulting in increasing AME (Fig 6D). This experiment demonstrated the quantitative nature of the PHAM method.

For tRNA ${ }^{\text {Ser }}$ AGA the substantial reduction of ACL signal after the highest wash temperature revealed reproducible appearance of an upper band, which unlike the lower band, did not decrease as the fraction of $t_{i t}^{+}$RNA increased (Fig 6B, ACL probe, bottom panel, left to right, and data not shown). Inspection analysis of duplicate blots suggest the following plausible explanation. The upper band reflects a precursortRNA ${ }^{\text {Ser }}$ AGA that has not acquired $i^{6} \mathrm{~A} 37$ in tit $^{+}$nor tit1 $\Delta$ cells prior to its processing to the mature size tRNA. Accordingly, the unmodified upper band would exhibit efficient ACL probe annealing relative to mature tRNA-i ${ }^{6} \mathrm{~A} 37$. As $S$. pombe tRNA ${ }^{\text {Ser }} \mathrm{AGA}$ genes do not contain introns, the upper band may reflect a nuclear pre-tRNA ${ }^{\text {Ser }}$ AGA isodecoder with a unique 3'-trailer, e.g., tRNA-Ser-AGA 1-3 (Chan and Lowe 2015).

\section{PROTOCOL}

Total RNA isolation. Use a method applicable to the organism of choice. Importantly, be aware that some RNA purification kits, methods and protocols are mistakenly misnamed useful for "Total RNA" which refers to inclusion of rRNA vs. purification of poly(A) and are oblivious to- and designed to- exclude tRNAs 
and smaller species by precipitation with $\mathrm{LiCl}$ or sizing columns. A broad-use method for extraction and purification from tissues or cells is one based on guanidinium thiocyanate-acidic phenol (MacDonald et al. 1987; Maraia 1991) which is similar to Trizol /Tripure (Invitrogen/Sigma) based methods that use e.g., ammonium acetate followed by alcohol precipitation to not exclude tRNAs (see below).

Total RNA isolation from yeast. Here we used the acidic hot phenol method to isolate total RNA from S. cerevisiae and S. pombe. Transfer an overnight yeast culture to a $50 \mathrm{ml}$ conical flask containing $10 \mathrm{ml}$ of media at $\mathrm{OD}_{600} \sim 0.1$ and grow to mid $\log$ phase $\left(\mathrm{OD}_{600} \sim 0.55\right)$ at $30^{\circ} \mathrm{C}$ for $S$. cerevisiae, $32^{\circ} \mathrm{C}$ for $S$. pombe.

Transfer the culture to a $50 \mathrm{ml}$ centrifuge tube and spin at $3000 \mathrm{rpm}$ for $3 \mathrm{~min}$ at $4^{\circ} \mathrm{C}$. Discard the supernatant and resuspend pellet in $1 \mathrm{ml}$ ice cold $\mathrm{ddH}_{2} \mathrm{O}$. Transfer the culture to a $1.5 \mathrm{ml}$ microcentrifuge tube, pellet by centrifugation at $8000 \mathrm{rpm}$ for $1 \mathrm{~min}$ at $4^{\circ} \mathrm{C}$. Discard the supernatant. Resuspend the cell pellet in $400 \mu \mathrm{l}$ TES solution (10 mM Tris-HCl pH 7.5, $10 \mathrm{mM}$ EDTA, 0.5\% SDS) followed by addition of $400 \mu \mathrm{l}$ acid phenol (Sigma P4682). Close the cap tightly. Vortex vigorously for $30 \mathrm{sec}$ and incubate in a shaker for 1 hour at $65^{\circ} \mathrm{C}$; alternatively frequent brief vortexing can also be done.

Incubate on ice for $5 \mathrm{~min}$ and spin down at 12K rpm (benchtop centrifuge, e.g. 12-16K x g) for 5 min at $4^{\circ} \mathrm{C}$. Carefully transfer the aqueous phase (top) to a clean, RNase-free $1.5 \mathrm{ml}$ microcentrifuge tube (use extreme care to not approach, penetrate, disturb, or aspirate any of the white interphase material). Add 400 $\mu l$ acid phenol (Sigma P4682) to the separated aqueous phase, vortex vigorously, incubate on ice for 5 min and centrifuge at $12 \mathrm{~K} \mathrm{rpm}$ for $5 \mathrm{~min}$ at $4^{\circ} \mathrm{C}$. Again, transfer the aqueous phase to a clean, RNase-free 1.5 $\mathrm{ml}$ microcentrifuge tube, add $400 \mu \mathrm{l}$ chloroform, vortex vigorously and repeat the centrifugation step. Transfer the aqueous phase to a clean, RNase-free $1.5 \mathrm{ml}$ microcentrifuge tube, add $40 \mu \mathrm{l}$ of $3 \mathrm{M}$ sodium acetate $\mathrm{pH} 5.3$, mix well and add 1-ml ice cold $100 \%$ ethanol, mix again and incubate for $\geq 1$ hour, or overnight at $-20^{\circ} \mathrm{C}$. Centrifuge at $12 \mathrm{~K} \mathrm{rpm}$ for $5 \mathrm{~min}$ at $4{ }^{\circ} \mathrm{C}$. Visualize the pellet and wash it with $1 \mathrm{ml}$ of ice cold $70 \%$ ethanol, vortex and centrifuge briefly at max speed. Visualize the pellet, sharply invert the 
tube to decant the supernatant onto paper towel. Air-dry the pellet for $10 \mathrm{~min}$ at room temperature. Be careful to not over-dry, do not use a vacuum dryer, if the pellet is too dry the RNA will not dissolve well. Total RNA isolation from mammalian cells (see total RNA isolation above). Standard Trizol/Tripure (Invitrogen/Sigma)-based methods can be used. This protocol is for HEK293 cells cultured in media of choice. Combining 2 wells of a 6-well plate will yield more than enough RNA to perform the PHAM assay. Harvest cells at 70-80\% confluency. Wash twice with $2 \mathrm{ml}$ PBS per well followed by addition of $500 \mathrm{ul}$ TriPure per well. Transfer all solution, $1 \mathrm{ml}$, to a $1.5 \mathrm{ml}$ centrifuge tube. Add $200 \mu \mathrm{l}$ chloroform (Sigma 2432) and shake vigorously for 15 seconds, incubate at room temperature for $2 \mathrm{~min}$. Centrifuge at 12,000 $\mathrm{xg}$ for $15 \mathrm{~min}$ at $4^{\circ} \mathrm{C}$.

Carefully transfer the (top) aqueous phase only to a RNase-free $1.5 \mathrm{ml}$ tube (use extreme care to not approach penetrate, disturb or aspirate any of the white interphase material). Add 450 ul isopropanol to the isolated aqueous phase. Mix thoroughly by inversion several times, with intermittent vortexing. Incubate at room temperature for $5 \mathrm{~min}$ and centrifuge at $12,000 \mathrm{x} \mathrm{g}, 4^{\circ} \mathrm{C}$ for $10 \mathrm{~min}$. Visualize the pellet then wash it at least three times with $1 \mathrm{ml} \mathrm{75 \%}$ ethanol, vortexing each time shortly and centrifuging for 2 mins at max speed between each wash. Visualize the pellet, sharply invert the tube to decant the supernatant onto paper towel. Air-dry pellet for 10 min at room temperature. Be careful to not over-dry, do not use a vacuum dryer (if the pellet is too dry the RNA will not dissolve well).

At this point it is important to minimize the time that purified RNA will be in aqueous solution susceptible to hydrolysis/degradation. Resuspend the pellet in $30 \mu \mathrm{RNase}$-free ddH2O. Keep at room temperature for 5 mins, vortex once or twice very shortly and spin down, make sure the pellet is completely dissolved. Remove an aliquot to be used to quantify the RNA concentration and immediately put the tube with the remainder of the RNA into a bucket of dry ice to rapid-freeze then transfer to $-80^{\circ} \mathrm{C}$.

Northern blot preparation, part 1: Urea-denaturing polyacrylamide gel electrophoresis of RNA. We use pre-cast 10\% TBE-Urea gels (Thermofisher, EC68752BOX) run in XCell SureLock Mini-Cell (EI0001, 
Thermofisher), however, other precast or home-made TBE-Urea gels and running systems can be used. Slowly and carefully remove the comb from the gel, noting any misshaped wells due to difficult comb removal. Consider use of a soft, thin pipette tip with $1 \mathrm{x}$ TBE to expunge loose polyacrylamide from the bottom of the wells and to straighten walls of the wells. Pre-run in $1 \mathrm{x}$ TBE running buffer at 180V for 30 min. During the pre-run the $8 \mathrm{M}$ urea denaturant will diffuse from the gel into the wells, it is not necessary to remove this denaturant; one can carefully load the sample under it in the lowest part of the well. The sample will remain under the urea layer (do not puncture or misshape the well as it will misshape the bands). RNA sample preparation, loading buffer and gel loading. Add an equal volume of prewarmed 2X RNA RNase-free loading dye (NEB B0363S, 95\% formamide, 0.02\% SDS, 0.02\% bromophenol blue, 0.01\% Xylene cyanole, $1 \mathrm{mM}$ EDTA) to 5 or $10 \mu \mathrm{g}$ of each total RNA sample and heat denature at $70^{\circ} \mathrm{C}$ for 3 min. Load directly from the heat block to prevent renaturation, by placing at the bottom of the well.

Load the gel by slow pipetting samples at the bottom of the wells. Run at $180 \mathrm{~V}$ until the xylene cyanole (XC, the upper dye) reaches near but not run-off the bottom of the gel ( $\sim 1.5 \mathrm{hr})$. In 10\% TBE-Urea PAGE, $\mathrm{XC}$ has mobility corresponding to a 55-nt single stranded DNA.

Gel dismantling, RNA staining with ethidium bromide and photo documentation. Put on a clean gloves and wash in $\mathrm{ddH}_{2} \mathrm{O}$. Whatever contacts the gel surface from this point onward may transfer to the blot membrane and affect the hybridization results. Be prepared to note and keep track of the position of lane 1 so to mark it immediately after dismantling the gel from the electrophoresis apparatus. With a clean rinsed spatula/knife, slice off a substantial triangular lower gel segment under lane 1 as an important orientation marker to which a similar triangle will be cut from the nylon blot membrane of matching dimensions. Shake the gel in substantial volume of $\mathrm{ddH}_{2} \mathrm{O}$ containing $\leq 0.01 \mathrm{ug} / \mathrm{ml} \mathrm{EtBr}$ for $5 \mathrm{~min}$, followed by $3 \times 10 \mathrm{~min}$ washes with $\mathrm{ddH}_{2} \mathrm{O}$. Take a high quality full-gel picture on a UV illuminator using minimal exposure time and intensity to avoid UV damage to the RNA. Keep the gel wet until ready to transfer. 
Northern prep part 2: Transfer RNA to membrane, mark-up, UV-crosslink \& vacuum dry. Key to obtaining clean results is preparation of a clean blot, free of unwanted micro-debris and other ${ }^{32} \mathrm{P}-\mathrm{ATP}$ interacting material that may bond to the membrane as indelible sources of background noise for every probing. Good blots crosslinked and baked can be useful for more than ten tRNA ACL-BP probe cycles.

Transfer RNA from the gel using a semi-dry or wet transfer method to a positive charge nylon membrane (Gene Screen Plus, Perkin Elmer) that has been pre-cut fit with a triangle to match that under lane 1 of the gel. Rinse the gel and set it on the transfer stage using plenty of liquid to prevent it from getting stretched and deformed and to ease away wrinkles. Rinse the gel surface before placing a clean rinsed membrane on it. We find it useful to stream transfer buffer from a pipette over the gel surface to clear away micro-debris including tiny polyacrylamide particles before putting the membrane on it. Ensure that the membrane and gel are correctly situated/oriented according to proper function of the apparatus. Add a prewet filter paper and remove air bubbles by rolling a plastic pipette over the assembly. Add some buffer to make sure the conduction, and thus the transfer will be optimal. For semi-dry blotting allow liquid between membrane and gel to absorb away.

After transfer is complete, dissemble the blot keeping track of which side of the blot was in contact with the gel/RNA. Place the blot on a clean damp Whatman 3MM paper with its RNA surface facing up and write on it with a sharp point marker under lane 1. Clean both sides of the membrane surface including of any polyacrylamide specs or micro-debris that may have attached during transfer, prior to UV crosslinking. Quickly rinse the membrane briefly in $2 \mathrm{X} \mathrm{SSC}$, allow it to drip damp then UV crosslink at $254 \mathrm{~nm}$ wavelength with the RNA-side facing the UV source (in a Stratalinker UV-1800, Stratagene) on auto-crosslink mode. The membrane should be damp, not dry during crosslinking. It is important at this moment to note and document (mark it) which side of the membrane has the RNA because it will have significant effects on the efficiencies of i) UV crosslinking, ii) hybridization, iii) exposure to phosphorimager and/or X-ray film, thereby affecting the resolution of the bands observed, reproducibility of hybridization and quantification of one tRNA to the next, and therefore the overall success of the 
experiment. If you have a hand-held UV lamp you should verify that one side has RNA and not the other (it should be apparent); this may also reveal irregularities (bubbles) in the transfer. After letting the membrane dry, label it on the side that contains the transferred RNA, along the bottom edge with your initials, the date and other unique identifying information, making an indelible impression with a marker or ball point pen. Next, thoroughly dry the membrane preferably by baking at $80^{\circ} \mathrm{C}$ for $2 \mathrm{hr}$. under vacuum.

Blot prehybridization \& hybridization; set-up. Except for probe in the latter, prehybridization and hybridization buffers are the same: $2 \mathrm{X}$ SSC $+1 \mathrm{X}$ Denhardt's solution $+0.5 \% \mathrm{SDS}+100 \mu \mathrm{g} / \mathrm{ml}$ yeast total RNA (Invitrogen AM7118) from Torula, related to S. cerevisiae. Note: do not use this RNA for analysis of S. cerevisiae RNA, it will decrease detection; use sheared Salmon sperm DNA (Invitrogen AM9680).

We use dry ovens of two types for probe hybridization, with rotating glass cylindrical sealed tubes (Techne Hybrigene), or with a flat rocking platform that holds a container of choice. Advantage of the rocking platform is the blot(s) can be more easily placed into and removed from the container than from the cylinders. This also helps avoid air bubbles and other irregularities/ difficulties associated with cylinders such as placement of blots. Also, membranes tend not to "free float" in the cylinders but rather stick to the glass, sometimes trapping air bubbles. It is therefore very important to apply the membrane with the RNAside surface facing the solution. If other options are unavailable a water bath can be used for hybridization, best if the blot is in a water-tight pouch using a plastic bag sealer and submerged with shaking at the $\mathrm{Ti}^{\circ} \mathrm{C}$.

Rehydrate the blot with 2X SSC buffer and transfer it into the hybridization tube/container with the RNA-side facing the solution. Add $14 \mathrm{ml}$ prehybridization buffer and incubate at the DNA-oligo probespecified Ti for $\geq 1-2$ hours with optimal access of all parts of the blot to the solution.

Blot hybridization: There is no need to discard the prehybridization buffer. The ${ }^{32} \mathrm{P}$ radioactive labeled DNA-oligo probe (below) that has been heat denatured for $10 \mathrm{~min}$ at $65^{\circ} \mathrm{C}$ in $1 \mathrm{ml}$ of hybridization buffer is added to the blot-incubation $14 \mathrm{ml}$ solution and further incubated for $8-16$ hours at $\mathrm{Ti}^{\circ} \mathrm{C}$. When labeled to high specific activity (below) DNA-oligo probes are used at 2 million $\mathrm{cpm} / \mathrm{ml}$ of hybridization solution. 
For $15 \mathrm{ml}$ hybridization, incubate 30 million $\mathrm{cpm}^{32} \mathrm{P}$-DNA probe in $0.5-1 \mathrm{ml}$ hybridization solution for 5 min at $80^{\circ} \mathrm{C}$ just before adding this to the pre-heated hybridization solution already on the blot. Add the ${ }^{32} \mathrm{P}$-DNA probe solution to the hybridization liquid while mixing rather than directly onto the membrane.

Hybridization uses a large excess of probe and time allowing equilibrium annealing important for reproducible results and quantification. Caution: Alteration of the recommended conditions, including reduced probe amounts (below) and/or use to quantify high abundance e.g., rRNAs can fail due to probe exhaustion/consumption and non-equilibrium conditions. For quantification of high abundance rRNA, addition of a large excess of unlabeled DNA-oligo identical to the labeled probe is suggested.

Initial washing at the Ti: The next day, pre-heat $2 \mathrm{XSSC}, 0.1 \%$ SDS and hold it at the Ti. Carefully decant all the ${ }^{32} \mathrm{P}$ hybridization solution to appropriately labeled holding container behind plexiglass shield for possible reuse. Completely drain all remaining liquid from hybridization vessel to radiation waste container. Using a flat head blunt end Millipore filter forceps, transfer the blot to a clean tray with RNA-side up. It is useful to monitor washing of the probe; examine the blot with a Geiger counter, noting approximate cpm on the $0.1 \mathrm{X}, 1 \mathrm{X}$ or $10 \mathrm{X}$ meter, and the distance of the recorder above the membrane and in vicinity of expected bands. Be sure that there is no contaminating source of radioactivity nearby, including under the tray. Add $150 \mathrm{ml}$ of room temperature wash buffer (2X SSC, $0.1 \%$ SDS). Rinse the hybridization vessel with wash buffer and decant in the radioactive waste. Add wash buffer to the incubation vessel and place it back in the hybridization oven to shake/rotate to clean the vessel further and keep it at Ti. Decant the wash buffer on the blot in the radioactive waste and wash the blot 2 more times for 5 mins at room temperature with $150 \mathrm{ml}$ wash buffer and perform a final wash of the blot with $20 \mathrm{ml}$ of the pre-heated wash buffer in the hybridization vessel at Ti for 30 minutes. Repeat examination of the blot, RNA-side up with the Geiger counter and note the cpm, which should have decreased substantially.

Seal the blot in plastic, wrinkle-free and with minimal liquid and air bubbles, so the RNA-side is visible and will be in close/direct contact with a phosphorimager screen or X-ray film. If necessary, place filler cardboard behind the blot to press it closely against the screen for high resolution bands. 
It is wise to obtain multiple exposures for long and short times. When not in use, blots in sealed/wrapped plastic should be put in storage folder for protection from light, $\mathrm{UV}$, and scratches/damage to their surface, in the refrigerator, preferably in a hard notebook, for reuse (subsequent probing).

Rewashing at temperatures above Ti: It is recommended that blots are rewashed at multiple increments of $5^{\circ} \mathrm{C}$ and/or $2.5^{\circ} \mathrm{C}$ above the Ti with autoradiography after each such wash is complete, until the majority of signal is removed from the sample that represents the target modification-containing sample. Wet the blot with wash buffer at room temperature then discard. Pour $20 \mathrm{ml}$ prewarmed wash buffer and incubate for 30 minutes at the new wash temperature. In accordance with calculations for DNA-oligo melting (Leonard G. Davis 1986), it should be expected that exposure times be lengthened after increases in wash temperature in order to achieve sufficient signal above background useful for quantitative purposes. Use the Geiger counter method to follow the progress of each subsequent wash.

Stripping blots for reuse: A general principle of strategy for the order of which probes to employ before others is to first examine tRNAs with probes expected to give the weakest signals, i.e., ACL probes followed by sequential stringent washing against multiple different tRNAs, less abundant before more abundant, before hybridizing with body probes. This is because stronger signals due to more abundant RNA are generally more refractory to stripping. The most abundant RNAs including loading controls will last as the most enduring as the blot is sequentially stripped of its RNA and "wears out" due to repeated reuse.

Protect the blot from unnecessarily harsh stripping. Use the Geiger counter as a guide. Most conditions will require stripping of a previously annealed probe, especially if it will block analysis of the second probe. If the previous probe is to a different RNA and is no longer visible it does not necessarily need to be stripped away. However, a pre-exposure of the blot before a re-probing should always be done to ensure that no bands will be present that may confound the new probing results. Also, if a blot with efficiently annealed probe inadvertently dries it may become 'fixed' to the tRNA and block subsequent reprobings.

To strip, pour pre-heated stripping buffer $(0.1 \mathrm{X} \mathrm{SSC}+0.1 \% \mathrm{SDS})$ at $85-90^{\circ} \mathrm{C}$, onto the blot with RNAside up, and shake with incubation for $10 \mathrm{~min}$. Confirm removal of the ${ }^{32} \mathrm{P}$ labelled DNA probe using a 
phosphorimager for at least several hours. Save the image, quantitate the signals, and calculate the signal per pixel ("counts") per minute of exposure time, which may be important for later analysis.

DNA-oligo probe 5'-end labeling and purification. In an Eppendorf tube mix: $\bullet 10 \mu 1$ desired DNA-oligo $(1 \mathrm{pmol} / \mu \mathrm{L})($ more than $10 \mathrm{pmol}$ deceases specific activity of the probe), $\bullet 3.3 \mu \mathrm{l} 10 \mathrm{X}$ PNK buffer (final reaction volume is $33 \mu \mathrm{L}$ ), $\bullet 1$ of T4 PNK (NEB), $\bullet 5 \mu{ }^{32} \mathrm{P}-\gamma \mathrm{ATP}$ (allow time to defrost, Perkin Elmer, BLU002A001MC, $3000 \mathrm{Ci} / \mathrm{mmol}$, at $3.3 \mu \mathrm{M}$ ), • add $\mathrm{H} 2 \mathrm{O}$ to final volume of no more than $33 \mu \mathrm{L}$ (final ATP concentration should be $\geq 1 \mu \mathrm{M})$. Mix by pipetting up and down. Incubate at $37^{\circ} \mathrm{C}$ for $1-1.5$ hour. Stop the reaction by adding $4 \mu \mathrm{L}$ of $0.5 \mathrm{M}$ EDTA $(\mathrm{pH} 8.0)$.

Carefully apply the total mixture onto the center of a freshly packed, i.e., centrifuged Sephadex MicroSpin G-25 column (GE Healthcare) that is in a $1.5 \mathrm{ml}$ Eppendorf tube. Spin $2 \mathrm{~min}$ at $750 \mathrm{x} \mathrm{g}$ in a microcentrifuge. The flow through into the Eppendorf has the labeled ${ }^{32} \mathrm{P}$-probe, -the column retains the unincorporated ${ }^{32} \mathrm{P}-\gamma$ ATP. Carefully measure and record with a Geiger counter the relative amounts of ${ }^{32} \mathrm{P}-$ rATP in each, the Eppendorf, and the resin/column. Record the volume of the probe liquid fraction recovered, in microliters for future reference and calculation of SA (specific activity).

If the flow through in the Eppendorf tube has $\geq 70 \%$ of the total ${ }^{32} \mathrm{P}$-cpm, the separation of the labeled DNA-oligo from free ${ }^{32} \mathrm{P}-\gamma$ ATP was likely inefficient, i.e., it contains free ${ }^{32} \mathrm{P}-\gamma \mathrm{ATP}$. Too much free ${ }^{32} \mathrm{P}-$ $\gamma$ ATP can be a source of dirty hybridizations and high blot background that cannot be washed away, obscuring tRNA bands and making quantification difficult or impossible. Therefore, repeat the purification by applying the flow-through material onto one or two freshly prepared Sephadex MicroSpin G-25 columns (overloading can lead to poor column performance).

Determine Specific Activity (SA) of ${ }^{32} \mathbf{P}$-labeled probe: Using appropriate scintillation fluid measure the cpm of the probe in the final flow-through using a scintillation counter. To do this also make duplicate $1 / 10^{\text {th }}$ and $1 / 50^{\text {th }}$ dilutions of the probe, measure and convert to $\mathrm{cpm} / \mu \mathrm{L}$ probe. This is used to calculate SA. 
Calculate SA based on starting amount of oligo, i.e., assume $100 \%$ recovery, expressed as cpm/ $\mu \mathrm{g}$ probe: $\mathrm{SA}=\mathrm{cpm} / \mu \mathrm{g}$ probe for purposes below. Optimally SA can be $>10^{9} \mathrm{cpm} / \mathrm{ug}$ oligo DNA of $\sim 24 \mathrm{nt}$, or $10^{6} \mathrm{cpm} / \mathrm{pmole}$.

Guidelines for DNA-oligo probe design. Modification-sensitive probes are designed according to similar principles; a near central position in the DNA-oligo targets the modified nucleotide in the tRNA. DNAoligo lengths are typically 20-25 nt depending on $\mathrm{G}+\mathrm{C}$-content which determines $\mathrm{Tm}$ (melting temperature), based on the formula: $\mathrm{Tm}=[16.6 \log \lceil\mathrm{M}]+0.41(P \mathbf{g c})+81.5-(675 / L)-0.65]$ (Leonard G. Davis 1986). Here, $\mathrm{M}=$ molar concentration of $\mathrm{Na}^{+}$, to a maximum of $0.5\left(2 \mathrm{X} \mathrm{SSC}=0.39 \mathrm{M} \mathrm{Na}^{+}\right.$; saline-sodium citrate buffer $\left.=0.3 \mathrm{M} \mathrm{NaCl}, 30 \mathrm{mM} \mathrm{Na}_{3} \mathrm{C}_{6} \mathrm{H}_{5} \mathrm{O}_{7}\right), P_{\mathbf{g c}}=\% \mathrm{G}+\mathrm{C}$ content, and $L=$ nucleotide length of the DNA-oligo (Leonard G. Davis 1986). The Ti is $15^{\circ} \mathrm{C}$ lower than the Tm.

As discussed above, avoid covering a nearby nucleotide that is part of a modification circuit and/or whose modification alters base pairing. Use similar guidance to design the body probe (BP) used as a control. Distribution, frequencies and other information about tRNA modifications can be found at http://genesilico.pl/trnamodviz (Machnicka et al. 2014).

An Excel file in the Supplementary materials (Supp Table S1) will automatically calculate the Tm, Ti, and other information, after the 5'-to-3'sequence of the DNA-oligo probe (complementary to the tRNA) is entered into the appropriate space in column C. The file can also serve as an inventory of probe sequences. Quantification of tRNA-detected bands by DNA-oligo probes for calculation of AME. Scan blots using a phosphorimager (GE-Typhoon FLA 9500, Storm, FujiFilm or similar equipment with large dynamic range). Quantify bands using Multi Gauge V3.0 (Fujifilm) or other appropriate (ImageQuant) software.

\section{DISCUSSION}

PHAM is a relatively accessible and versatile method that has been used in several laboratories to examine 
$i^{6} \mathrm{~A} 37, \mathrm{t}^{6} \mathrm{~A} 37, \mathrm{~m}^{2,2} \mathrm{G} 26$ and $\mathrm{m}^{3} \mathrm{C} 32$ levels on numerous tRNAs in 14 publications. Yet, during use of the method in our lab over the past several years, variability was observed that we suspect is common due to the nature of hybridization technology. It is typical for PHAM blot data to compare signals from the ACL (or other target region) probe and the control probe, by visual inspection, or accompanied by quantification and expressed as a ratio or modification index, sometimes with inexplicable variability for similar modification-sensitive probes for different tRNAs. Here we report that our attempts to understand and minimize the variability led to an overall improved method that more reliably produces optimal results. Most notably, we found that despite guidance by a formula to estimate DNA-oligo melting temperature (Tm) and hybridization incubation (Ti) (Leonard G. Davis 1986), when used on the heavily modified structured cellular tRNAs, each probe-tRNA pair should be tested empirically, subjected to multiple increasing wash temperature increments above the calculated Ti.

That the PHAM method is versatile refers to the multiple times a blot can be used to obtain data for several different tRNAs/modifications. In addition to the empiric conditions that must be determined for each tRNA-probe pair the first time characterized, other limitations apply. PHAM would not be expected to locate positions of previously unknown modifications. Also, although northern blotting normally uses agarose gels for large RNAs, PHAM uses polyacrylamide-urea gels which yield high resolution separation. Finally, PHAM alone does not identify a modification nor is a standard for absolute quantification, other gold standard methods are available (see Helm and Motorin 2017).

Improved PHAM conditions revealed new findings and clarified previous results. Although it might be suspected that a second modified base that is complementary to an ACL probe would interfere with annealing, it was not previously documented. Our data suggest that the commonly modified $\mathrm{m}^{2,2} \mathrm{G} 26$ found on many tRNAs (see Arimbasseri et al. 2015) can lead to substantial false increases in calculated AMEs when the target ACL nucleotide of interest is modified at relatively low levels. This was important to demonstrate because it suggests scrutiny when comparing samples for example when a TME is partially 
inactivated to different extents by different mutations. Thus, Fig 5 illustrated and emphasized the importance of careful probe design.

Another advance revealed by data in this report is that apparently similar tRNAs can respond very differently to near identical washings. A comparison case was $S$. pombe cy-tRNA ${ }^{\text {Trp }} \mathrm{CCA}$ and mttRNA ${ }^{\text {Trp }}$ CCA whose sequences at 73 and 72 nts are also of the same clover-leaf architecture. Although these tRNAs have ACLs of identical primary sequence and the respective ACL probes differ by $\leq 1^{\circ} \mathrm{C}$ in $\mathrm{Ti}$, their wash profiles differed significantly (Fig 4).

The disparity for mt-tRNAs was important because it helped clarify previous unresolved results. Attempts to quantify i ${ }^{6} \mathrm{~A} 37$ modification of S. pombe and human mt-tRNAs by PHAM led to calculated levels of $\sim 25 \%$ and $\sim 50 \%$ washing at Ti for mt-tRNAs whereas cy-tRNAs showed substantially higher levels (Lamichhane et al. 2013a; Lamichhane et al. 2013b; Lamichhane et al. 2016), consistent with Fig 4. More specifically, human mt-tRNA ${ }^{\text {Ser (UCN) }}$ and mt-tRNA ${ }^{\text {Trp }}$ were estimated at $50 \%$ and $40 \%$, whereas mt-tRNA ${ }^{\text {Cys }}$ was $\leq 10 \%$ by PHAM, the latter much lower than noted at $99 \%$ for mt-tRNA ${ }^{\text {Cys }}$ determined by gold standard methods (Suzuki et al. 2020). Although we have not systematically re-examined/quantified human mt-tRNAs, it was reassuring to find that the calculated AME for S. pombe mt-tRNA ${ }^{\operatorname{Trp}}$ was increased to $95 \%$ after $\mathrm{Ti}+15^{\circ} \mathrm{C}$ (Fig 4C). We suspect that the disparity observed between responses of mt-and cy- tRNAs to ACL probes of similar length and $\mathrm{Ti}$, reflect overall general differences in flexibility/rigidity of their anticodon stemloop structures and consequent ability to stably pair with DNA-oligo (Vare et al. 2017).

A third advance is that the PHAM assay was subjected to a calibration analysis of its ability to estimate AME for tRNA fractional $i^{6} \mathrm{~A} 37$ content by examining RNAs that contained different relative amounts of modified and unmodified tRNAs from yeast TME replete and deleted strains (Fig 6). This provides confidence in calculations of AME including when the content of tRNA from the modified source was as low as $25 \%$ (Fig 6). This suggests that it may be possible to monitor significant loss of other modifications, for example $\mathrm{m}^{1} \mathrm{~A}$ at specific mRNA sites using PHAM, although this remains to be determined. 
Advancing molecular studies of TMEs and effects on substrate-tRNA modifications. Deficiency in a TME can lead to differential effects on distinct tRNA substrates. The PHAM assay can be considered as an alternative to LC-MS/MS and other methods (see introduction) to detect $\mathrm{i}^{6} \mathrm{~A} 37, \mathrm{~m}^{2,2} \mathrm{G} 26, \mathrm{~m}^{3} \mathrm{C} 32$, and $\mathrm{t}^{6} \mathrm{~A} 37$. It has been used to document tRNA hypomodification resulting from newly described TME deficiencies resulting in human disease syndromes due to mutations in TRIT1 (Yarham 2014), TRMT1 (Dewe et al. 2017), DALRD3 (Lentini et al. 2020), and OSGEP (Edvardson et al. 2017), respectively.

OSGEP is encoded by the KAE1 gene and is one of five subunits of the human KEOPS (kinase,

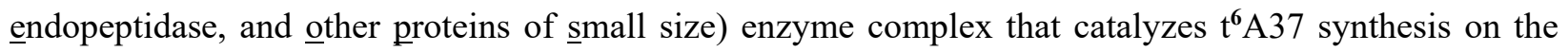
multitude of cy-tRNAs that decode ANN codons (Edvardson et al. 2017). Not too long after the initial report of neurodegeneration and evidence of kidney pathophysiology associated with kae1-mutations and hypomodification of $\mathrm{t}^{6} \mathrm{~A} 37$, it was reported that mutations in genes encoding all four of the other KEOPS subunits lead to Galloway-Mowat syndrome (Braun et al. 2017; Arrondel et al. 2019). Yeast KEOPS is comprised of four subunits (apparently lacking a Gon7 homolog) all of which contribute to substrate tRNA binding, and mutations in each of which cause $\mathrm{t}^{6} \mathrm{~A} 37$ hypomodification of multiple tRNAs as monitored by PHAM (Beenstock et al. 2020).

A pathogenic mutation in a mt-tRNA sequence can lead to hypomodification at another position, for example if it alters a TME substrate recognition site, as was shown using PHAM for the A38G mutation in mt-tRNA ${ }^{\text {Ser (UCN) }}$ resulting in tRNA-i ${ }^{6}$ A37 hypomodification (Yarham 2014). It seems reasonable to expect that the PHAM method can be extended to molecular studies and other pathogenic mutations, including those involved in tRNA modifications that disrupt base pairing, such as $\mathrm{m}^{1} \mathrm{~A}, \mathrm{~m}^{1} \mathrm{G}$ and $\mathrm{yW}$.

\section{ACKNOWLEDGEMENTS}

This work was supported by the Division of Intramural Research, Eunice Kennedy Shriver National Institute of Child Health and Human Development, NIH, Bethesda, MD, United States. RM, SM and AK would like to thank M. Bayfield for discussion, and to acknowledge the NICHD Scientific Director's Award. 


\section{REFERENCES}

Abbott JA, Francklyn CS, Robey-Bond SM. 2014. Transfer RNA and human disease. Front Genet 5: 158. Abelson H, Johnson L, Penman St, Green H. 1974. Changes in RNA in relation to growth of the fibroblast: II. The lifetime of mRNA, rRNA, and tRNA in resting and growing cells. Cell 1: 161-165.

Agris PF, Eruysal ER, Narendran A, Väre VYP, Vangaveti S, Ranganathan SV. 2018. Celebrating wobble decoding: Half a century and still much is new. RNA Biol 15: 537-553.

Arimbasseri AG, Blewett NH, Iben JR, Lamichhane TN, Cherkasova V, Hafner M, Maraia RJ. 2015. RNA polymerase III output is functionally linked to tRNA dimethyl-G26 modification. PLoS Genetics 11: e1005671.

Arimbasseri AG, Iben J, Wei FY, Rijal K, Tomizawa K, Hafner M, Maraia RJ. 2016. Evolving specificity of tRNA 3-methyl-cytidine-32 (m3C32) modification: a subset of tRNAsSer requires N6isopentenylation of A37. RNA 22: 1400-1410.

Arrondel C, Missoury S, Snoek R, Patat J, Menara G, Collinet B, Liger D, Durand D, Gribouval O, Boyer O et al. 2019. Defects in t(6)A tRNA modification due to GON7 and YRDC mutations lead to Galloway-Mowat syndrome. Nat Commun 10: 3967.

Bacusmo JM, Orsini SS, Hu J, DeMott M, Thiaville PC, Elfarash A, Paulines MJ, Rojas-Benitez D, Meineke B, Deutsch C et al. 2018. The t(6)A modification acts as a positive determinant for the anticodon nuclease PrrC, and is distinctively nonessential in Streptococcus mutans. RNA Biol 15: 508-517.

Barraud P, Tisné C. 2019. To be or not to be modified: Miscellaneous aspects influencing nucleotide modifications in tRNAs. IUBMB Life 71: 1126-1140.

Bednarova A, Hanna M, Durham I, VanCleave T, England A, Chaudhuri A, Krishnan N. 2017. Lost in Translation: Defects in Transfer RNA Modifications and Neurological Disorders. Frontiers in Molecular Neuroscience $\mathbf{1 0 .}$

Beenstock J, Ona SM, Porat J, Orlicky S, Wan LCK, Ceccarelli DF, Maisonneuve P, Szilard RK, Yin Z, Setiaputra D et al. 2020. A substrate binding model for the KEOPS tRNA modifying complex. Nat Commun 11: 6233.

Behrens A, Rodschinka G, Nedialkova DD. 2021. High-resolution quantitative profiling of tRNA abundance and modification status in eukaryotes by mim-tRNAseq. Mol Cell 81: 1802-1815 e1807.

Boccaletto P, Machnicka MA, Purta E, Piatkowski P, Baginski B, Wirecki TK, de Crecy-Lagard V, Ross R, Limbach PA, Kotter A et al. 2018. MODOMICS: a database of RNA modification pathways. 2017 update. Nucleic Acids Res 46: D303-D307.

Braun DA Rao J Mollet G Schapiro D Daugeron MC Tan W Gribouval O Boyer O Revy P Jobst-Schwan $\mathrm{T}$ et al. 2017. Mutations in KEOPS-complex genes cause nephrotic syndrome with primary microcephaly. Nat Genet 49: 1529-1538.

Chan PP, Lowe TM. 2015. GtRNAdb 2.0: an expanded database of transfer RNA genes identified in complete and draft genomes. Nucleic Acids Res 44(D1): 44(D41):D184-189.

Chujo T, Tomizawa K. 2021. Human transfer RNA modopathies: diseases caused by aberrations in transfer RNA modifications. Febs $j$.

Cirzi C, Tuorto F. 2021. Analysis of Queuosine tRNA Modification Using APB Northern Blot Assay. Methods Mol Biol 2298: 217-230.

Clark WC, Evans ME, Dominissini D, Zheng G, Pan T. 2016. tRNA base methylation identification and quantification via high-throughput sequencing. RNA 22: 1771-1784.

Cozen AE, Quartley E, Holmes AD, Hrabeta-Robinson E, Phizicky EM, Lowe TM. 2015. ARM-seq: AlkBfacilitated RNA methylation sequencing reveals a complex landscape of modified tRNA fragments. Nat Methods 12: 879-884.

Dewe JM, Fuller BL, Lentini JM, Kellner SM, Fu D. 2017. TRMT1-Catalyzed tRNA Modifications Are Required for Redox Homeostasis To Ensure Proper Cellular Proliferation and Oxidative Stress Survival. Mol Cell Biol 37. 
Edvardson S, Prunetti L, Arraf A, Haas D, Bacusmo JM, Hu JF, Ta-Shma A, Dedon PC, de Crecy-Lagard V, Elpeleg O. 2017. tRNA N6-adenosine threonylcarbamoyltransferase defect due to KAE1/TCS3 (OSGEP) mutation manifest by neurodegeneration and renal tubulopathy. Eur J Hum Genet 25: 545-551.

Gogakos T, Brown M, Garzia A, Meyer C, Hafner M, Tuschl T. 2017. Characterizing expression and processing of precursor and mature human tRNAs by hydro-tRNAseq and PAR-CLIP. Cell Reports 20: $1463-1475$.

Guo LT, Adams RL, Wan H, Huston NC, Potapova O, Olson S, Gallardo CM, Graveley BR, Torbett BE, Pyle AM. 2020. Sequencing and Structure Probing of Long RNAs Using MarathonRT: A NextGeneration Reverse Transcriptase. J Mol Biol 432: 3338-3352.

Guy MP, Phizicky EM. 2014. Conservation of an intricate circuit for crucial modifications of the tRNAPhe anticodon loop in eukaryotes. RNA.

Guy MP, Shaw M, Weiner CL, Hobson L, Stark Z, Rose K, Kalscheuer VM, Gecz J, Phizicky EM. 2015. Defects in tRNA Anticodon Loop 2'-O-Methylation Are Implicated in Nonsyndromic X-Linked Intellectual Disability due to Mutations in FTSJ1. Hum Mutat.

Han L, Guy MP, Kon Y, Phizicky EM. 2018. Lack of 2'-O-methylation in the tRNA anticodon loop of two phylogenetically distant yeast species activates the general amino acid control pathway. PLoS Genet 14: e1007288.

Han L, Phizicky EM. 2018. A rationale for tRNA modification circuits in the anticodon loop. RNA.

Helm M, Motorin Y. 2017. Detecting RNA modifications in the epitranscriptome: predict and validate. Nat Rev Genet 18: 275-291.

Hiley SL, Jackman J, Babak T, Trochesset M, Morris QD, Phizicky E, Hughes TR. 2005. Detection and discovery of RNA modifications using microarrays. Nucleic Acids Res 33: e2.

Hrabeta-Robinson E, Marcus E, Cozen AE, Phizicky EM, Lowe TM. 2017. High-Throughput Small RNA Sequencing Enhanced by AlkB-Facilitated RNA de-Methylation (ARM-Seq). Methods Mol Biol 1562: 231-243.

Igloi GL, Kössel H. 1985. Affinity electrophoresis for monitoring terminal phosphorylation and the presence of queuosine in RNA. Application of polyacrylamide containing a covalently bound boronic acid. Nucleic Acids Res 13: 6881-6898.

Kessler AC, Kulkarni SS, Paulines MJ, Rubio MAT, Limbach PA, Paris Z, Alfonzo JD. 2018. Retrograde nuclear transport from the cytoplasm is required for tRNA(Tyr) maturation in T. brucei. RNA Biol 15: $528-536$.

Khalique A, Mattijssen S, Haddad AF, Chaudhry S, Maraia RJ. 2020. Targeting mitochondrial and cytosolic substrates of TRIT1 isopentenyltransferase: Specificity determinants and tRNA-i6A37 profiles. PLoS Genet 16: e1008330.

Krutyholowa R, Zakrzewski K, Glatt S. 2019. Charging the code - tRNA modification complexes. Curr Opin Struct Biol 55: 138-146.

Lamichhane TN, Arimbasseri AG, Rijal K, Iben JR, Wei FY, Tomizawa K, Maraia RJ. 2016. Lack of tRNA-i6A modification causes mitochondrial-like metabolic deficiency in S. pombe by limiting activity of cytosolic tRNATyr, not mito-tRNA. RNA 22: 583-596.

Lamichhane TN, Blewett NH, Cherkasova VA, Crawford AK, Iben JR, Farabaugh PJ, Begley TJ, Maraia RJ. 2013a. Lack of tRNA modification isopentenyl-A37 alters mRNA decoding and causes metabolic deficiencies in fission yeast. Mol Cell Biol 33: 2918-2929.

Lamichhane TN, Blewett NH, Maraia RJ. 2011. Plasticity and diversity of tRNA anticodon determinants of substrate recognition by eukaryotic A37 isopentenyltransferases. RNA 17: 1846-1857.

Lamichhane TN, Mattijssen S, Maraia RJ. 2013b. Human cells have a limited set of tRNA anticodon loop substrates of the tRNA isopentenyltransferase TRIT1 tumor suppressor. Mol Cell Biol 33: 49004908.

Lentini J, Bargabos R, Chen C, Fu D. 2021. METTL8 is required for 3-methylcytosine modification in human mitochondrial tRNAs. bioRxiv (not peer reviewed). 
Lentini JM, Alsaif HS, Faqeih E, Alkuraya FS, Fu D. 2020. DALRD3 encodes a protein mutated in epileptic encephalopathy that targets arginine tRNAs for 3-methylcytosine modification. Nat Commun 11: 2510 .

Leonard G. Davis MDDaJFB. 1986. Basic Methods in Molecular Biology. Elsevier.

Li J, Wang YN, Xu BS, Liu YP, Zhou M, Long T, Li H, Dong H, Nie Y, Chen PR et al. 2020. Intellectual disability-associated gene ftsj1 is responsible for 2'-O-methylation of specific tRNAs. EMBO Rep 21: e50095.

Lorenz C, Lünse CE, Mörl M. 2017. tRNA Modifications: Impact on Structure and Thermal Adaptation. Biomolecules 7.

MacDonald RJ, Swift GH, Przybyla AE, Chirgwin JM. 1987. Isolation of RNA using guanidinium salts. In Methods in Enzymology, Vol 152 (ed. SL Berger, AR Kimmel), pp. 219-226. Academic Press, Inc., Boston.

Machnicka MA, Olchowik A, Grosjean H, Bujnicki JM. 2014. Distribution and frequencies of posttranscriptional modifications in tRNAs. RNA Biol 11: 1619-1629.

Maraia R. 1991. The subset of mouse B1 (Alu-equivalent) sequences expressed as small processed cytoplasmic transcripts. Nucl Acids Res 19: 5695-5702.

Matuszek Z, Pan T. 2019. Quantification of Queuosine Modification Levels in tRNA from Human Cells Using APB Gel and Northern Blot. Bio Protoc 9: e3191.

Motorin Y, Bec G, Tewari R, Grosjean H. 1997. Transfer RNA recognition by the Escherichia coli delta2isopentenyl-pyrophosphate:tRNA delta2-isopentenyl transferase: dependence on the anticodon arm structure. RNA 3: 721-733.

Motorin Y, Marchand V. 2021. Analysis of RNA Modifications by Second- and Third-Generation Deep Sequencing: 2020 Update. Genes (Basel) 12.

Nostramo RT, Hopper AK. 2020. A Novel Assay Provides Insight into tRNA $<$ sup $>$ Phe $</$ sup $>$ Retrograde Nuclear Import and Re-export in S. cerevisiae. Nucleic Acids Research.

Pan T. 2018. Modifications and functional genomics of human transfer RNA. Cell Res 28: 395-404.

Rojas-Benitez D, Thiaville PC, de Crecy-Lagard V, Glavic A. 2015. The Levels of a Universally Conserved tRNA Modification Regulate Cell Growth. J Biol Chem 290: 18699-18707.

Ryvkin P, Leung YY, Silverman IM, Childress M, Valladares O, Dragomir I, Gregory BD, Wang LS. 2013. HAMR: high-throughput annotation of modified ribonucleotides. RNA 19: 1684-1692.

Sokolowski M, Klassen R, Bruch A, Schaffrath R, Glatt S. 2017. Cooperativity between different tRNA modifications and their modification pathways. Biochim Biophys Acta.

Suzuki T. 2021. The expanding world of tRNA modifications and their disease relevance. Nat Rev Mol Cell Biol 22: 375-392.

Suzuki T, Yashiro Y, Kikuchi I, Ishigami Y, Saito H, Matsuzawa I, Okada S, Mito M, Iwasaki S, Ma D et al. 2020. Complete chemical structures of human mitochondrial tRNAs. Nat Commun 11: 4269.

Vare VY, Eruysal ER, Narendran A, Sarachan KL, Agris PF. 2017. Chemical and Conformational Diversity of Modified Nucleosides Affects tRNA Structure and Function. Biomolecules 7.

Wang X, Matuszek Z, Huang Y, Parisien M, Dai Q, Clark W, Schwartz MH, Pan T. 2018. Queuosine modification protects cognate tRNAs against ribonuclease cleavage. RNA 24: 1305-1313.

Wei FY, Zhou B, Suzuki T, Miyata K, Ujihara Y, Horiguchi H, Takahashi N, Xie P, Michiue H, Fujimura A et al. 2015. Cdk5rap1-mediated 2-methylthio modification of mitochondrial tRNAs governs protein translation and contributes to myopathy in mice and humans. Cell Metab 21: 428-442.

Yarham JW, Lamichhane, T., Mattijssen, S., Bruni, F., McFarland, R., Maraia, R.J., Taylor, R.W. 2014. Defective i6A37 Modification of Mitochondrial and Cytosolic tRNAs Results from Pathogenic Mutations in TRIT1 and its Substrate tRNA. PLoS Genetics 10: e1004424.

Zaborske JM, DuMont VL, Wallace EW, Pan T, Aquadro CF, Drummond DA. 2014. A nutrient-driven tRNA modification alters translational fidelity and genome-wide protein coding across an animal genus. PLoS Biol 12: e1002015. 
Zhang W, Xu R, Matuszek Ż, Cai Z, Pan T. 2020. Detection and quantification of glycosylated queuosine modified tRNAs by acid denaturing and APB gels. RNA 26: 1291-1298.

Zheng G, Qin Y, Clark WC, Dai Q, Yi C, He C, Lambowitz AM, Pan T. 2015. Efficient and quantitative high-throughput tRNA sequencing. Nat Methods 12: 835-837. 


\section{FIGURE LEGENDS}

Figure 1. Schematic structures of modifications that interfere with W:C base pairing. A) The schematics show canonical Watson:Crick (W:C) base pairing through hydrogen bonding between Adenine (A):Thiamine (T) and Guanine (G):Cytosine (C). The $N^{1}$ and $N^{6}$ atoms of adenosine, $N^{1}$ and $N^{2}$ of guanosine, as well as $N^{3}$ and $\mathrm{C}^{5}$ of cytosine are indicated. B) Schematic structures of $N^{1}$-methyl-A (m $\left.{ }^{1} \mathrm{~A}\right)$, $N^{1}$-methyl-G $\left(\mathrm{m}^{1} \mathrm{G}\right)$, showing hydrogen bond disruption between A:T, G:C, respectively (compare with panel A). Inosine (I) and $N^{1}$-methylinosine $\left(\mathrm{m}^{1} \mathrm{I}\right)$ are also shown. C) $N^{3}$-methylcytosine $\left(\mathrm{m}^{3} \mathrm{C}\right)$ and $N^{2}, N^{2}$ dimethylguanosine $\left(\mathrm{m}^{2,2} \mathrm{G}\right)$ showing hydrogen bond disruption between $\mathrm{G}$ :C (compare panel A). D) The bulky, isopentenyl- and threonylcarbamoyl- groups attached to $N^{6}$ of adenosine-37 and another position-37 modification, wybutosine are shown. E) Illustration of PHAM assay results after separating total RNA from S. pombe yNB5 (tit1 $\Delta)$ and yYH1 (tit1+) on a 10\% TBE-Urea gel. Left top panel is the ethidium bromide-stained gel prior to transfer. Middle and lower panels show the ACL probe and corresponding Body probe results for to the same tRNA species (indicated to the left). On the right is the ACL probe oligo schematically indicated in red, it can bind efficiently only in the absence of the modification (asterisk), as in the Tit1-deleted strain. The body probe oligo is schematically indicated in blue.

Figure 2. Schematic outline representation of the PHAM method assay. See text for detailed protocol. A five-step protocol is outlined with brief descriptions (see text for details).

Figure 3. Different tRNAs exhibit different ACL probe wash profiles at temperatures above Ti. A and B) PHAM northern blot assay of total RNA from S. pombe yYH1 (tit1 $\left.{ }^{+}\right)$and yNB5 (tit1 $\left.\Delta\right)$. The figures show signals from the $\mathrm{i}^{6} \mathrm{~A} 37$-sensitive anticodon loop probe (ACL) probes specific to $S$. pombe cytRNA ${ }^{\text {Ser }}$ AGA (A), and cy-tRNA ${ }^{\text {Tyr }}$ GUA (B) after washing at temperatures indicated to the right of the panels, where $51.2^{\circ} \mathrm{C}$ and $54.3^{\circ} \mathrm{C}$ are the Tis for cy-tRNA ${ }^{\mathrm{Ser}} \mathrm{AGA}$ and cy-tRNA ${ }^{\mathrm{Tyr}} \mathrm{GUA}$, respectively. The T stem-loop body probe (BP) results are also shown. C) Graphic display of quantification of AME based 
on duplicate experiments for both tRNAs in A) and B) at different wash temperatures according to the

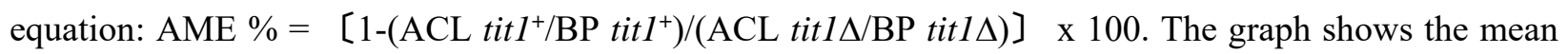
+/- standard deviation (error bars), $\mathrm{N}=2$ biological replicates.

Figure 4. ACL probes to mt-tRNAs can exhibit wide range or acute sensitivity to wash temperatures.

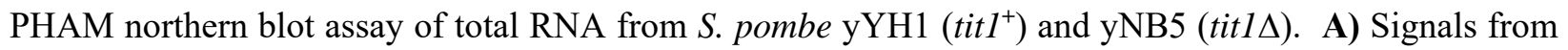

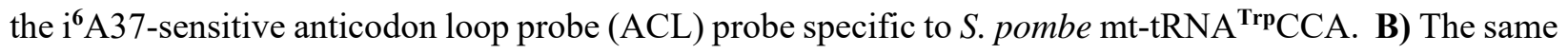
blot was examined for ACL hybridization to cy-tRNA ${ }^{\text {Trp }}$ CCA. The various wash temperatures are indicated to the right of the panels where $44.6^{\circ} \mathrm{C}$ and $45.2^{\circ} \mathrm{C}$ are the Tis for mt-tRNA ${ }^{\text {Trp }} \mathrm{CCA}$ and cy-tRNA ${ }^{\text {Trp }} \mathrm{CCA}$, respectively. T stem-loop body probe (BP) results are also shown. Quantification was done as for figure 3, on triplicate results, $\mathrm{N}=3$ biological replicates.

Figure 5. Nearby modifications may falsely alter the apparent modification efficiency of a target

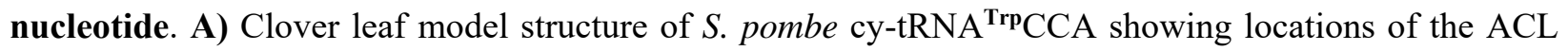
probe-1 (P1) in red, complementary to positions G26-G46, and ACL probe-2 (P2) in blue, complementary to positions G28-C48. The primary ACL modification-detection residue, A37 is indicated within a light blue circle, and the second modification site residue, G26 is indicated within a blue circle. The clover leaf model schematic was produced by tRNAscan-SE within GtRNAdb 2.0 (Chan and Lowe 2015). B) PHAM assay with total RNA from S. cerevisiae ABL8 $\left(M O D 5^{+}\right)$and MT8 (Mod5 $)$) cells transformed with $S$. pombe cy-tRNA ${ }^{\mathrm{Trp}} \mathrm{CCA}$ as one plasmid, together with an expression plasmid for S. cerevisiae Mod5, human TRIT1, S. pombe Tit1 or pREP82X empty vector as indicated above the lanes. Hybridization results with ACL probe-1 (P1, upper panel), ACL probe-2 (P2, middle) and body probe (BP, lower panel) are shown. C) Quantification of AME was as for figure 3 using the equation shown in the figure where \# would correspond to the lane in B to match panel C. 
Figure 6. Quantitative validation of the PHAM method using a yeast TME deletion control. A and B) PHAM assay results for cy-tRNA ${ }^{\text {Tyr }}$ GUA and cy-tRNA ${ }^{\text {Ser }}$ AGA on the same mixture of total RNAs purified from the yYH1 $\left(t i t 1^{+}\right)$and yNB5 (tit1 $)$strains as indicated above the lanes. The various wash temperatures are indicated to the right of the panels where $54.3^{\circ} \mathrm{C}$ and $51.2^{\circ} \mathrm{C}$ are the Tis for tRNA ${ }^{\mathrm{Tyr}} \mathrm{GUA}$ and cy-

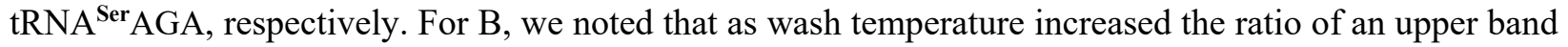
to the main, mature tRNA band increased. As S. pombe tRNA ${ }^{\text {Ser }}$ AGA genes do not contain introns, the upper band may reflect one or more nuclear unmodified pre-tRNA ${ }^{\text {Ser }}$ AGA isodecoders with a 3' trailer. C and D) Quantitation of AMEs were calculated from duplicate experiments at each different wash temperature using the following equation: $\mathrm{AME} \%=\left[1-\left(\mathrm{ACL} t i t 1^{+} / \mathrm{BP} t i t 1^{+}\right) /(\mathrm{ACL}\right.$ tit1 $\Delta / \mathrm{BP}$ tit1 $\left.\Delta)\right] \times 100 . \mathrm{N}=2$, error bars represent the SD. For C and D, linear regression using the trendline function of Microsoft Excel revealed $R^{2}$ values of $>0.985$ for the lines representing $\mathrm{Ti}+17.5^{\circ} \mathrm{C}$ and $\mathrm{Ti}+15^{\circ} \mathrm{C}$ (not shown). 
Figure 1, Khalique et al.
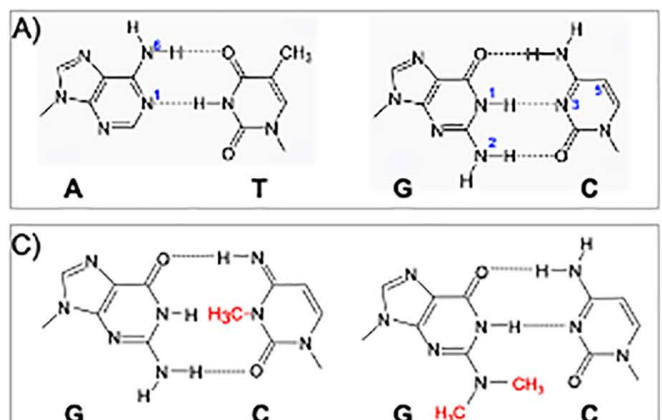

G

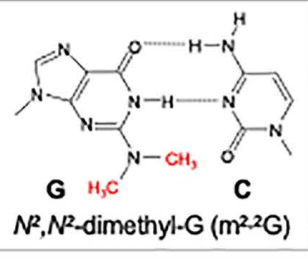

D)

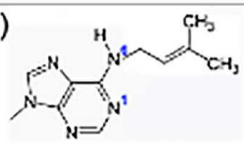

$N^{5}$-isopentenyl-A (i6 A)
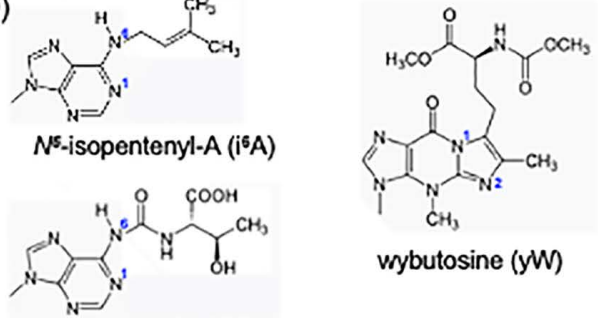

wybutosine (yW)
B)

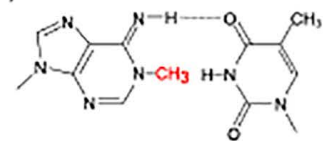

$N^{3}$-methyl-A (mª)

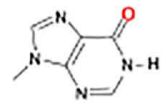

inosine, I

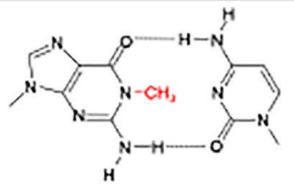

$N^{\top}$-methyl-G (m'G)

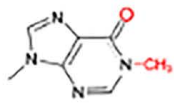

$N^{\top}$-methyl-inosine (m'I)
E) yNB5 (tit14) yYH1 (tit1+)

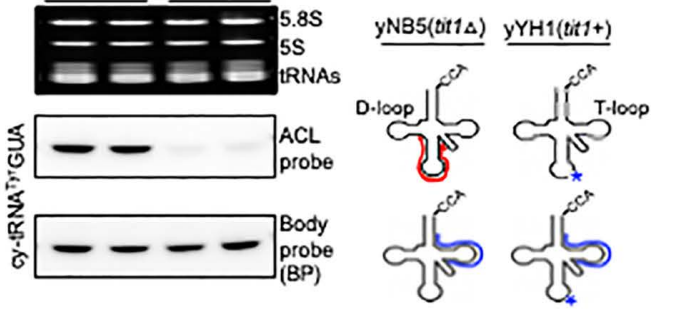


Figure 2, Khalique et al.

Step 1: Collect cells or tissue. Isolate and quantify total RNA.

Step 2: Sample preparation. TBE-Urea PAGE. Stain and pholograph gel.

Step 3: Transfer to membrane.

UV crosslink.

Bake under vacuum.

Step 4: Prehybridization and hybridization.

Expose to phosphorimager screen.

Scan by phosphorimager.

Quantification.

Step 5: Strip blot to remove probe.

Rescan and check for probe removal. Hybridization with new probe.
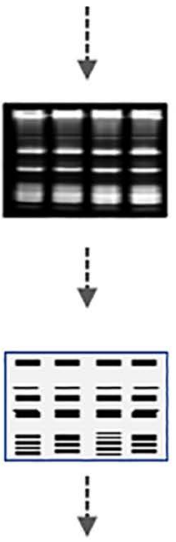

i

Mammalian, yeast, bacterial or other cells in culture, tissue.

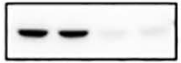

$\mathrm{ACL}$ probe
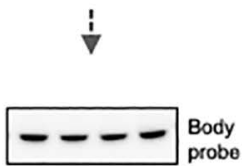

A minimum of 5 ug total RNA should be prepared. Typically, one million mammalian cells/sample or $10 \mathrm{ml}$ yeast culture.

RNA samples are loaded on TBE-urea PAGE. After electrophoresis, a triangular lower edge of gel under lane 1 is sliced away as marker for orientation later. Gel is washed in water containing $0.01 \mathrm{ug} / \mathrm{ml} \mathrm{EtBr}$ until urea soaks out. $\mathrm{Gel}$ is photographed.

RNA is transferred to a positive-charge nylon membrane followed by UV crosslinking $(254 \mathrm{~nm})$ and baked at $80^{\circ} \mathrm{C}$ for 2 hrs (in vacuum oven). This fixes RNA to the blot minimizing RNA loss during hybridization and washings, extending reuse for $>10$ reprobings.

Blot is incubated in prehybridization solution for $\geq 1 \mathrm{hr}$ prior to addition of $32 \mathrm{P}$ labeled oligo-DNA probe and hybridization overnight followed by sequential washing, and further processing as detailed in the text.

The first probe is removed by incubation of blot in stripping solution at $90^{\circ} \mathrm{C}$ (see text). Blot is rescanned to ensure probe removal. Then a new probe is annealed/hybridized. 

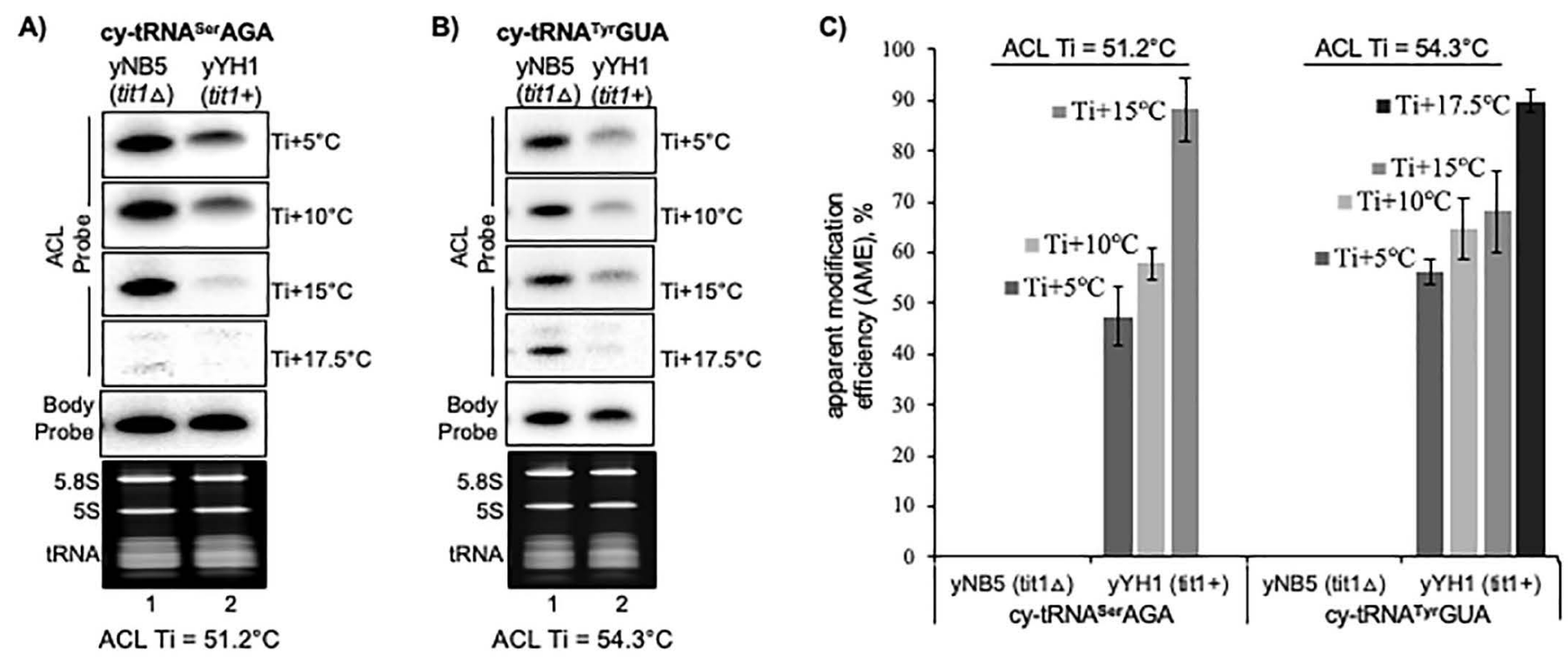
Figure 4, Khalique ot al.

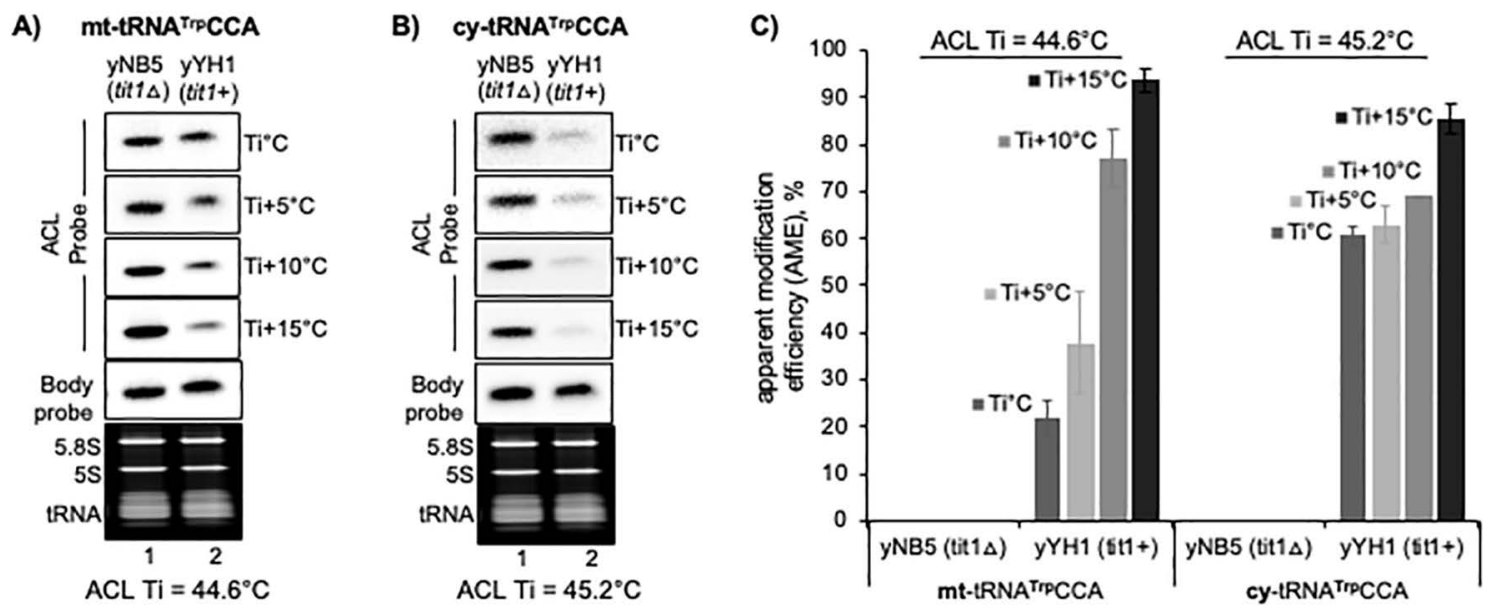


Figure 5, Khalique ot af.
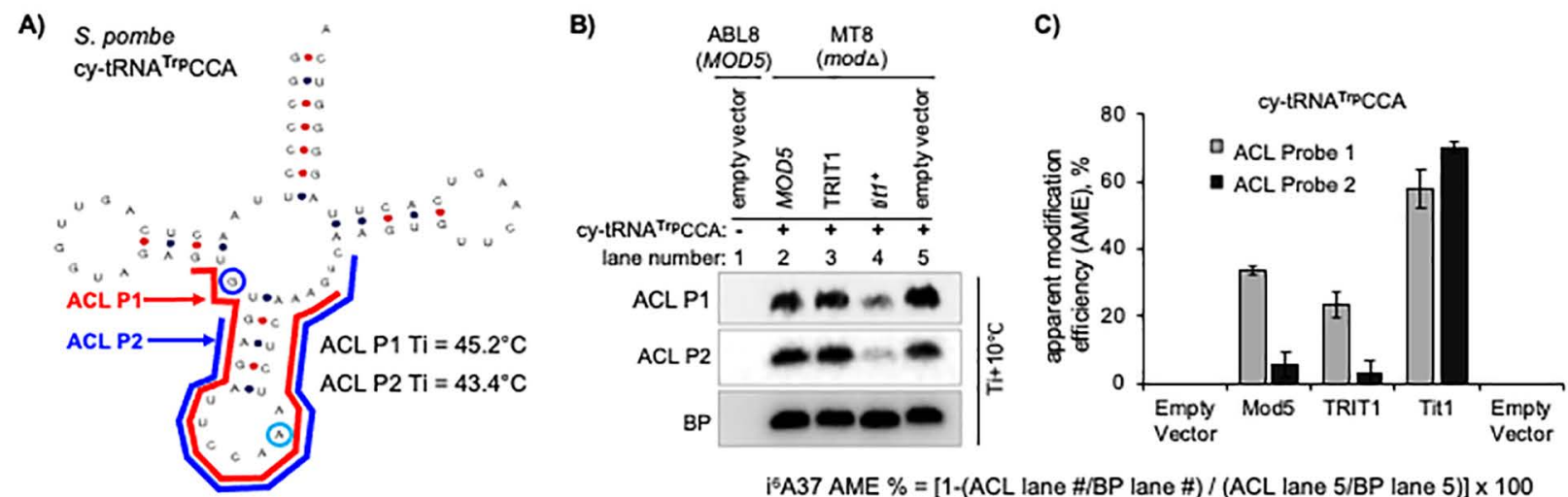

i5 A37 AME \% $=[1-(\mathrm{ACL}$ lane \#/BP lane \#) $/(\mathrm{ACL}$ lane 5/BP lane 5)] $\times 100$ 
A)

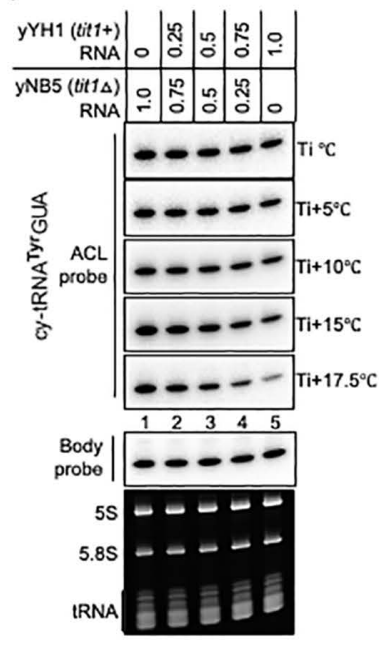

ACL $\mathrm{Ti}=54.3^{\circ} \mathrm{C}$
B)

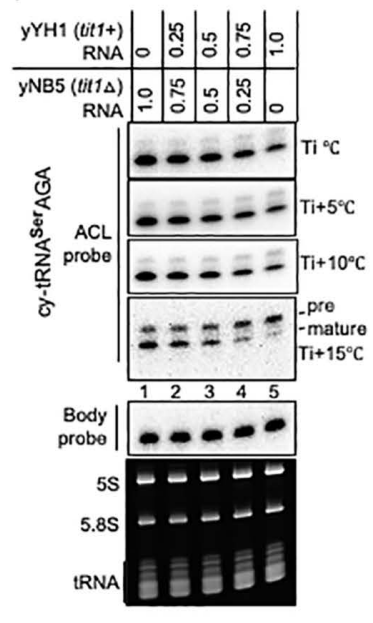

$A C L T i=51.2^{\circ} \mathrm{C}$
C)

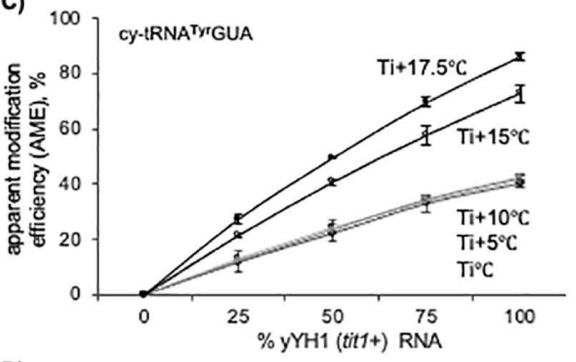

D)

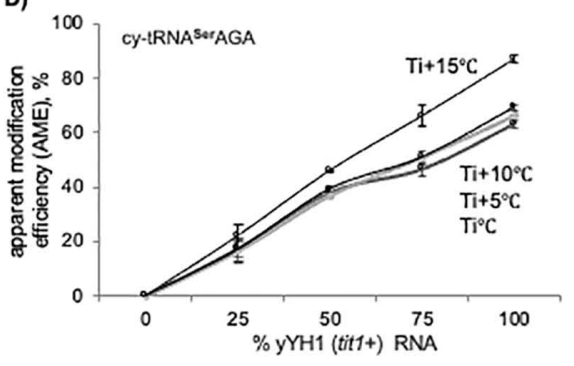



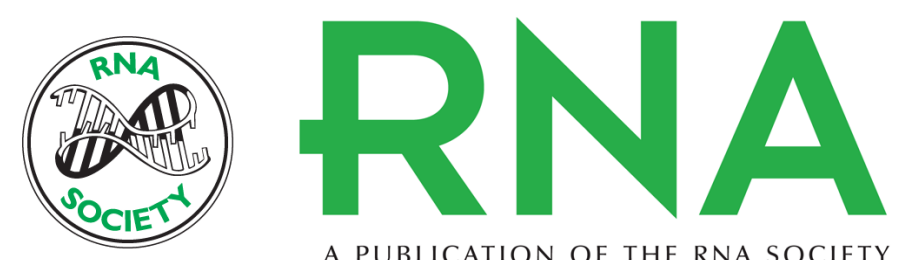

A PUBLICATION OF THE RNA SOCIETY

\section{A versatile tRNA modification-sensitive northern blot method with enhanced performance}

Abdul Khalique, Sandy Mattijssen and Richard J. Maraia

RNA published online December 20, 2021

Supplemental Material

$\mathbf{P}<\mathbf{P} \quad$ Published online December 20, 2021 in advance of the print journal.

Accepted Peer-reviewed and accepted for publication but not copyedited or typeset; accepted Manuscript manuscript is likely to differ from the final, published version.

Open Access Freely available online through the RNA Open Access option.

License This is a work of the US Government.

Email Alerting Receive free email alerts when new articles cite this article - sign up in the box at the Service top right corner of the article or click here.

To subscribe to RNA go to:

http://rnajournal.cshlp.org/subscriptions 